\title{
Paleomagnetismo do Neopaleozóico da Bacia Sanfranciscana, Noroeste de Minas Gerais
}

\author{
Daniele Brandt São Bernardo
}

\author{
Dissertação de Mestrado \\ Instituto de Astronomia, Geofísica e Ciências Atmosféricas \\ Universidade de São Paulo \\ Departamento de Geofísica \\ Orientadora: Marcia Ernesto \\ -2006-
}


Aos meus pais 


\section{RESUMO}

A curva de deriva polar aparente para o Palozóico Superior da América do Sul está baseada em pólos paleomagnéticos obtidos com base em metodologias que não são mais consideradas confiáveis e, portanto, necessita de dados mais bem determinados e com idades mais precisas.

$\mathrm{Na}$ Bacia Sanfranciscana (Noroeste de Minas Gerais) afloram rochas sedimentares pertencentes ao Grupo Santa Fé. Estas rochas pertencem ao final do Paleozóico, e constituem um registro glacial compreendendo arenitos, folhelhos e diamictitos, que compõem a Formação Floresta seguida da Formação Tabuleiro.

Para o estudo paleomagnético do Grupo Santa Fé amostrou-se arenitos e folhelhos vermelhos de 76 sítios independentes ao longo de quatro seções da Formação Floresta: duas seções do Membro Lavado, cada uma com 10 metros de espessura e outras duas do Membro Brejo do Arroz, sendo uma com 0.6 metros e outra com 9 metros de espessura. Após procedimentos detalhados de desmagnetização por campos magnéticos alternados e térmica, foi identificada uma única componente de magnetização muito estável (removida apenas à temperatura de $680^{\circ} \mathrm{C}$ ) cujos portadores são principalmente a hematita e, secundariamente, a magnetita. A magnetização remanente característica apresenta polaridade reversa compatível com o Superchron Reverso do Permo-Carbonífero (260-315Ma) e é de origem primária, como demonstram os testes de campo (comparação com a remanência do embasamento e de seixos pingados), e as evidências de que a hematita formou-se nos estágios iniciais da diagênese.

O pólo paleomagnético correspondente está situado a $332.8^{\circ} \mathrm{E}$ e $64.9^{\circ} \mathrm{S}(\mathrm{N}=60$; $\left.\alpha_{95}=4.1^{\mathrm{o}} ; \mathrm{k}=21\right)$ e representa um pólo de referência para o Paleozóico Superior (260280Ma). A reconstrução da América do Sul baseada nesse pólo descarta a possibilidade de uma reconstrução alternativa (Pangea B) para explicar as incongruências paleogeográficas apontadas na literatura. 


\begin{abstract}
The apparent polar wander path for Late Paleozoic of South America is based on paleomagnetic poles obtained with methodologies no longer considered reliable. Therefore new poles well determined with better constrained ages are needed.

In the Sanfranciscana Basin (Northwest Minas Gerais state) sedimentary rocks from the Santa Fé Group crop out. These rocks correspond to a glacial record of the Late Paleozoic, and lithologies are sandstones, shales and diamictites of the Floresta and and Tabuleiro formations.

For the paleomagnetic study sandstones and shales were sampled from 76 independent sites throughout four sections of Floresta Formation: two sections $(10 \mathrm{~m}$ thick) from Lavado Member, and two sections of Brejo do Arroz Member (0.6 and 9 meters thick). After detailed alternating field and thermal demagnetization procedures a unique characteristic remanence component (erased at $680^{\circ} \mathrm{C}$ ) was identified. Hematite is the main magnetic carrier but magnetite is also present. This characteristic magnetization is of reversed polarity compatible with the Permo-Carboniferous Reversed Superchron (260-315Ma), and is of primary origin as demonstrated by field tests (comparison with remanences of the basement rocks and of dropped stones), and laboratory evidences that hematite formed at initial stages of diagenesis.

The corresponding paleomagnetic pole is located at $332.8^{\circ} \mathrm{E}$ and $64.9^{\circ} \mathrm{S}(\mathrm{N}=60$; $\left.\alpha_{95}=4.1^{\mathrm{o}} ; \mathrm{k}=21\right)$, and represents a reference pole for the Late Paleozoic (260-280Ma). Reconstruction of South America based of the Santa Fé pole discard the alternative models (Pangea B) which were conceived to explain incongruencies in paleogeography of Pangea as discussed in literature.
\end{abstract}




\section{AGRADECIMENTOS}

Agradeço à Professora Dra. Marcia Ernesto pela orientação, acompanhamento e ensinamentos recebidos na realização deste trabalho.

Aos Professores Dr. Ricardo Ivan Ferreira da Trindade e Dr. Manoel Souza D'Agrella Filho pelas valiosas discussões durante a realização deste trabalho.

Aos Professores Dr. Antonio Carlos Rocha Campos e Dr. Paulo dos Santos pela assistência durante os trabalhos de campo.

Aos técnicos Cacilda Donizete Cruz Rodrigues, Helder Pinheiro Sampaio, Jefferson Carlos de Marins, José Airton Pinto e Rui Fernandes Oliveira pelo auxílio no laboratório com preparação de amostras e na solução de problemas com equipamentos e computadores.

Aos colegas do Laboratório de Paleomagnetismo pelas discussões e interesse neste trabalho.

Às amigas Lucieth e Alexandra pela grande ajuda com o texto e em geologia.

Aos meus pais Alfredo e Sandra Brandt, meus irmãos Desirée e Fellipe e meu marido Thiago por todo apoio, amor e paciência.

Aos professores da Geofísica pelos ensinamentos e a todos os funcionários do IAG-USP que contribuíram de forma direta ou indireta na realização deste trabalho.

A Fundação de Amparo à Pesquisa do Estado de São Paulo (FAPESP) pelo suporte financeiro, sem o qual este trabalho não se realizaria. 


\section{ÍNDICE}

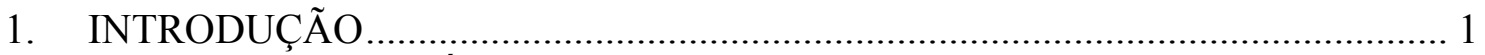

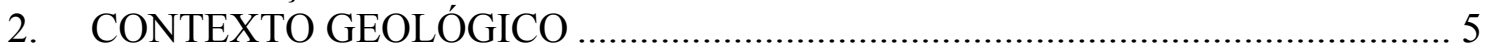

2.1. O Grupo Santa Fé ........................................................................... 5

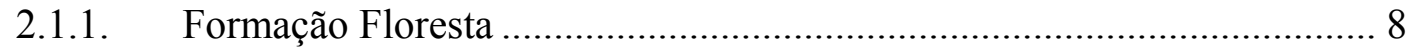

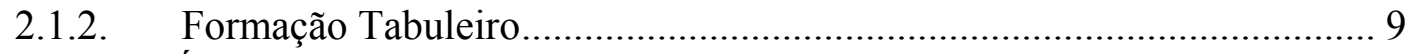

3. BASES FÍSICAS DO PALEOMAGNETISMO …………............................... 11

3.1. O Campo Geomagnético …………………………................................... 11

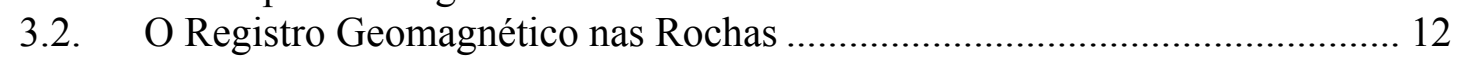

3.3. Principais Minerais Magnéticos .................................................................. 16

3.4. Magnetização Remanente......................................................................... 17

3.5. Métodos de Desmagnetização ...................................................................... 19

3.6. Análise das Componentes de Magnetização ………………………………..... 19

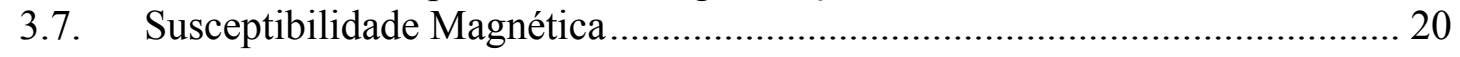

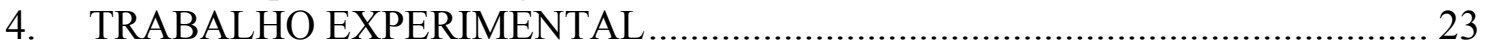

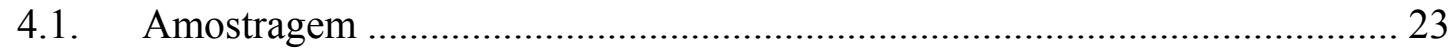

4.2. Preparação de Amostras .............................................................................. 26

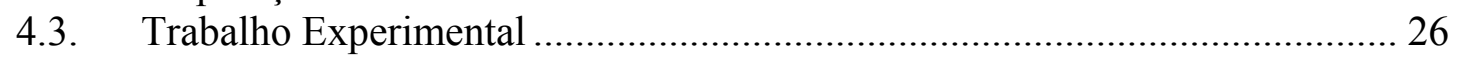

4.3.1. Anisotropia de susceptibilidade magnética …………………………..... 27

4.3.2. Desmagnetização por campos magnéticos alternados.............................. 30

4.3.3. Desmagnetização térmica ...................................................................... 31

4.4. Determinação das Componentes de Magnetização .......................................... 33

4.5. Caracterização da Mineralogia Magnética …………………………………... 35

4.5.1. Aquisição de magnetização induzida e teste de Lowrie ........................... 36

4.5.2. Observação de lâminas delgadas ............................................................. 38

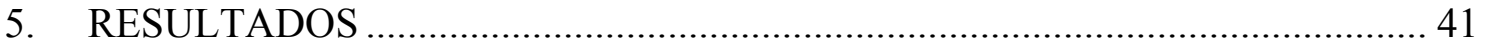

5.1. Testes da estabilidade da magnetização …………………………………..... 44

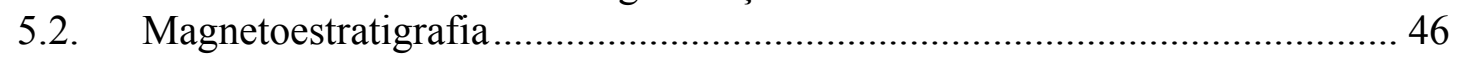

5.3. Pólos Geomagnéticos Virtuais...................................................................... 49

6. DISCUSSÕES E CONCLUSÕES ……………………................................. 51

6.1. Confiabilidade do Pólo Paleomagnético Santa Fé........................................... 51

6.2. Qualidade dos Pólos Paleomagnéticos da América do Sul ............................ 52

6.3. Idade do Grupo Santa Fé ............................................................................ 55

6.4. Paleogeografia e Paleolatitude .................................................................... 56

6.5. Considerações Finais ................................................................................ 59

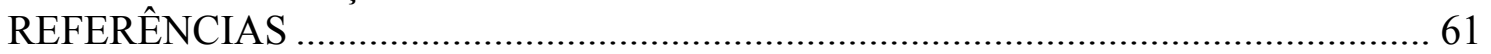




\section{INTRODUÇÃO}

Existem poucos pólos paleomagnéticos para o Paleozóico Superior da América do Sul que atendam aos critérios de confiabilidade aceitos na literatura atual. A maioria dos pólos disponíveis foram obtidos em décadas passadas, quando os recursos de análise da magnetização remanente das rochas e de análise mineralógica eram mais limitados. Em particular para o Paleozóico, grande parte dos dados resultam de rochas sedimentares que apresentam maiores limitações para a determinação de idades absolutas e confiáveis. Como conseqüência, a maioria dos pólos paleomagnéticos disponíveis têm idades muito indefinidas, com incertezas de até algumas dezenas de milhões de anos. Além disso, os resultados mais antigos foram obtidos com metodologias que não são mais consideradas confiáveis. Atualmente para a determinação de uma componente de magnetização requer-se desmagnetizações detalhadas e análise das componentes principais (Zijderveld, 1967; Kirschvink, 1980). Além disso os eventuais problemas tectônicos devem ser detectados e contornados através de testes de campo e correções adequadas.

Vários dos pólos disponíveis para o período Carbonífero Superior-Permiano Inferior provêm de regiões que mesmo afastadas da faixa andina, podem ter sido afetados por aqueles processos orogênicos (Geuna \& Escosteguy, 2003). Por esta razão, para uma melhor definição da curva de deriva polar aparente da América do Sul, é essencial a determinação de novos pólos paleomagnéticos de áreas estáveis da plataforma Sul Americana e que atendam aos critérios de qualidade (por exemplo, Van der Voo, 1990). Este trabalho apresenta um estudo paleomagnético de rochas sedimentares glaciais do Grupo Santa Fé de idade Permo-Carbonífera da Bacia Sanfranciscana, no estado de Minas Gerais.

O interesse particular em se realizar o estudo paleomagnético nessas rochas reside no fato de se tratar de redbeds, ou seja, rochas de coloração avermelhada devido à presença de hematita. A presença de hematita como principal portador da remanência magnética é um bom indicador da estabilidade da magnetização, devido à sua alta coercividade magnética. Entretanto, a origem da hematita pode significar um problema, porque muitas vezes aparece como mineral secundário, isto é, formado muito depois da 
deposição dos sedimentos. No caso das rochas sedimentares do Grupo Santa Fé, estudos anteriores mostraram que a origem da hematita data do início da diagênese dos sedimentos (Campos \& Dardenne, 1994), portanto existe alta probabilidade de ter guardado o registro do campo geomagnético dessa época. Neste caso, tanto a mineralogia quanto a magnetização remanente são consideradas primárias. Sendo assim, essas rochas sedimentares constituem um alvo em potencial capaz de satisfazer vários dos critérios de qualidade desejáveis para obtenção de um pólo paleomagnético de referência que contribua para uma melhor definição da CDPA da América do Sul.

Determinações de idade absolutas para formações sedimentares são raras e o controle de idade mais comum é a identificação de horizontes bioestratigráficos. Entretanto, as zonas bioestratigráficas às vezes são inexistentes ou mal definidas e, neste caso, a incerteza da informação inviabiliza a datação relativa. Neste contexto, dados paleomagnéticos associados a dados estratigráficos constituem a ferramenta mais precisa para definição da idade.

O intervalo compreendido entre o Paleozóico Superior e o Mesozóico Inferior é um período de grandes controvérsias relativas ao uso de dados paleomagnéticos em reconstruções globais. Esse debate persiste desde que Irving (1977) propôs uma configuração para o Pangea durante o Permiano-Triássico que diferia daquela já aceita para o Jurássico Inferior a Médio (Pangea de Wegener). A falta de consistência entre os pólos paleomagnéticos permianos-triássicos para a Laurússia e Gondwana na reconstrução típica de Wegener (Pangea A), foi interpretada por Irving (1977), bem como por outros autores desde então, como evidência de uma configuração diferente para o Pangea (Pangea B) para esse período.

Para atender à reconstrução do Jurássico, para a qual as bases de dados são coerentes, há a necessidade de se supor um cisalhamento destral por mais de $3.000 \mathrm{~km}$ entre Laurussia e Gondwana durante o Triássico, para migrar de uma configuração para outra, sendo que as evidências geológicas para esse tectonismo são muito tênues. Esta questão levou vários autores a acreditar que o problema residia na base de dados paleomagnéticos. De acordo com McElhinny \& McFadden (2000 e referências citadas) a fonte das discrepâncias reside na qualidade dos dados usados nas reconstruções e nas incertezas das idades. 
Van der Voo \& Torsvik (2001) por outro lado, questionaram a validade do modelo de dipolo geocêntrico e axial (GAD), como fonte de erro em dados paleomagnéticos. Em Paleomagnetismo utiliza-se a suposição de que o campo magnético terrestre, numa média temporal, corresponde ao campo produzido por um dipolo magnético paralelo ao eixo terrestre, no centro da Terra. Desta forma, o cálculo da paleolatitude ocupada por um certo local de amostragem, na época em que a unidade geológica adquiriu a magnetização remanente é condicionada a esse modelo. Entretanto, a hipótese da componente não-dipolar foi questionada e descartada por Muttoni et al. (2003).

Desta forma fica claro que há uma grande necessidade de se melhorar em quantidade e qualidade a base de dados paleomagnéticos da América do Sul correspondente ao Paleozóico Superior-Mesozóico Inferior, qualquer que seja a hipótese a ser investigada. Desta forma o estudo do Grupo Santa Fé apresentado neste trabalho, representa uma contribuição importante para resolver os problemas relativos à paleogeografia do período correspondente, bem como contribuir na definição da idade dessa formação geológica e nas questões da glaciação Permo-Carbonífera, no que diz respeito à duração e paleolatitudes. 


\section{CONTEXTO GEOLÓGICO}

A Bacia Sanfranciscana corresponde à cobertura Fanerozóica do Cráton São Francisco. Estende-se do Noroeste de Minas Gerais até o Sul do Piauí (Fig. 2.1), totalizando aproximadamente $1100 \mathrm{~km}$ de extensão e largura predominante de $200 \mathrm{~km}$ (Sgarbi et al., 2001). De acordo com Campos \& Dardenne (1997a), é dividida em duas sub-bacias: Abaeté e Urucuia devido a importantes diferenças entre as porções sul e norte da bacia.

As rochas mais antigas da Bacia Sanfranciscana pertencem ao Grupo Santa Fé, mas é possível que existam unidades ainda mais antigas não aflorantes. A sedimentação na Bacia Sanfranciscana iniciou-se no final do Paleozóico com os sedimentos glaciais do Grupo Santa Fé (Fig. 2.2). No Cretáceo Inferior ocorreu a deposição do Grupo Areado, posteriormente, no Cretáceo Superior ocorre a deposição dos grupos Mata da Corda e Urucuia, seguidos pela Formação Chapadão do Cenozóico.

\subsection{O Grupo Santa Fé}

A sedimentação do Grupo Santa Fé ocorreu devido a um "baixo relativo" por onde se canalizaram fluxos de centros glaciais vindos de SW para NNE, responsáveis pelas feições glaciogênicas do Grupo Santa Fé (Rocha-Campos et al., 2003).

O Grupo Santa Fé aflora na porção meridional da Bacia Sanfranciscana. Assentase sobre a Formação Três Marias do Grupo Bambuí (Proterozóico Superior) e é recoberta pela Formação Areado (Cretáceo Inferior). De acordo com Campos \& Dardenne (1994 e 1997a) e Sgarbi et al. (2001) o Grupo Santa Fé é composto por arenitos, siltitos, argilitos e diamictitos (tilitos e tilóides).

O posicionamento cronoestratigráfico do grupo Santa Fé no Permo-Carbonífero foi feito por Campos \& Dardenne (1994, 1997a) que consideram o Grupo Santa Fé correlato ao Grupo Itararé da Bacia do Paraná. Este grupo apresenta idade mínima de 260Ma baseada nas cinzas vulcânicas da Formação Rio Bonito que se sobrepõe imediatamente ao Grupo Itararé (Coutinho et al., 1991). 


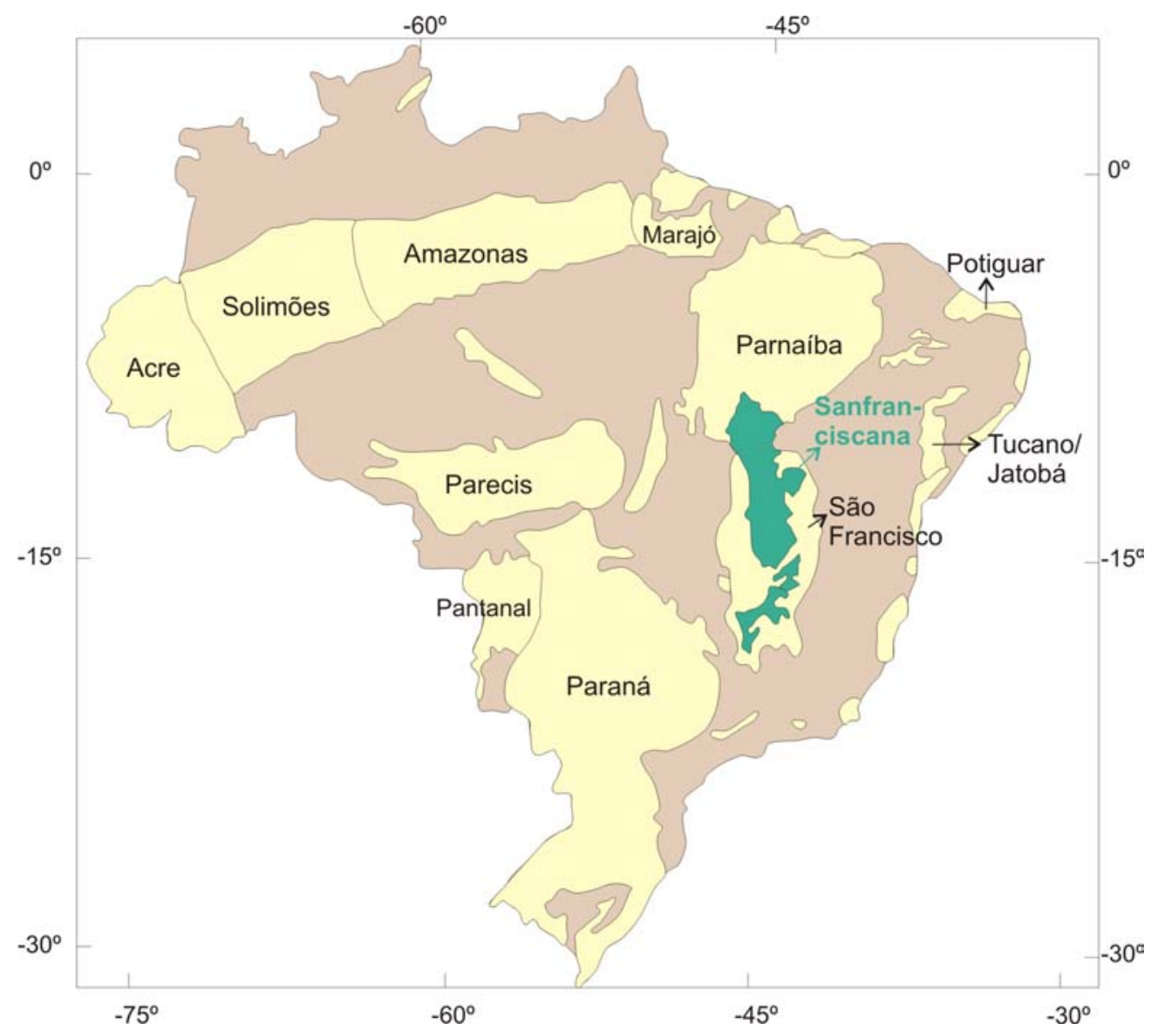

Figura 2.1. Localização das principais bacias da plataforma brasileira, destacando-se a Bacia Sanfranciscana (em verde). Baseado em Souza-Lima \& Junior (2003) e CPRM (2006).

Várias evidências apontam para uma origem glacial para as rochas do Grupo Santa Fé (Campos \& Dardenne, 1994; Dardenne \& Campos, 2003; Rocha-Campos et al., 2003): presença de pavimentos estriados (Formação Três Marias) com estruturas de roches moutonnées; seixos pingados com presença de estrias e faces polidas (Membro Brejo do Arroz); diamictitos não homogêneos e não estratificados (Membro Brocotó); ocorrência dos sedimentos em vales largos em "U" (indicador de escavações das capas de gelo).

O grupo Santa Fé é subdividido nas formações Floresta e Tabuleiro. A Formação Floresta é subdividida nos membros Brocotó, Brejo do Arroz e Lavado (nomenclatura baseada em feições geográficas e geomorfológicas da região). A Formação Tabuleiro recobre os membros da Formação Floresta. 


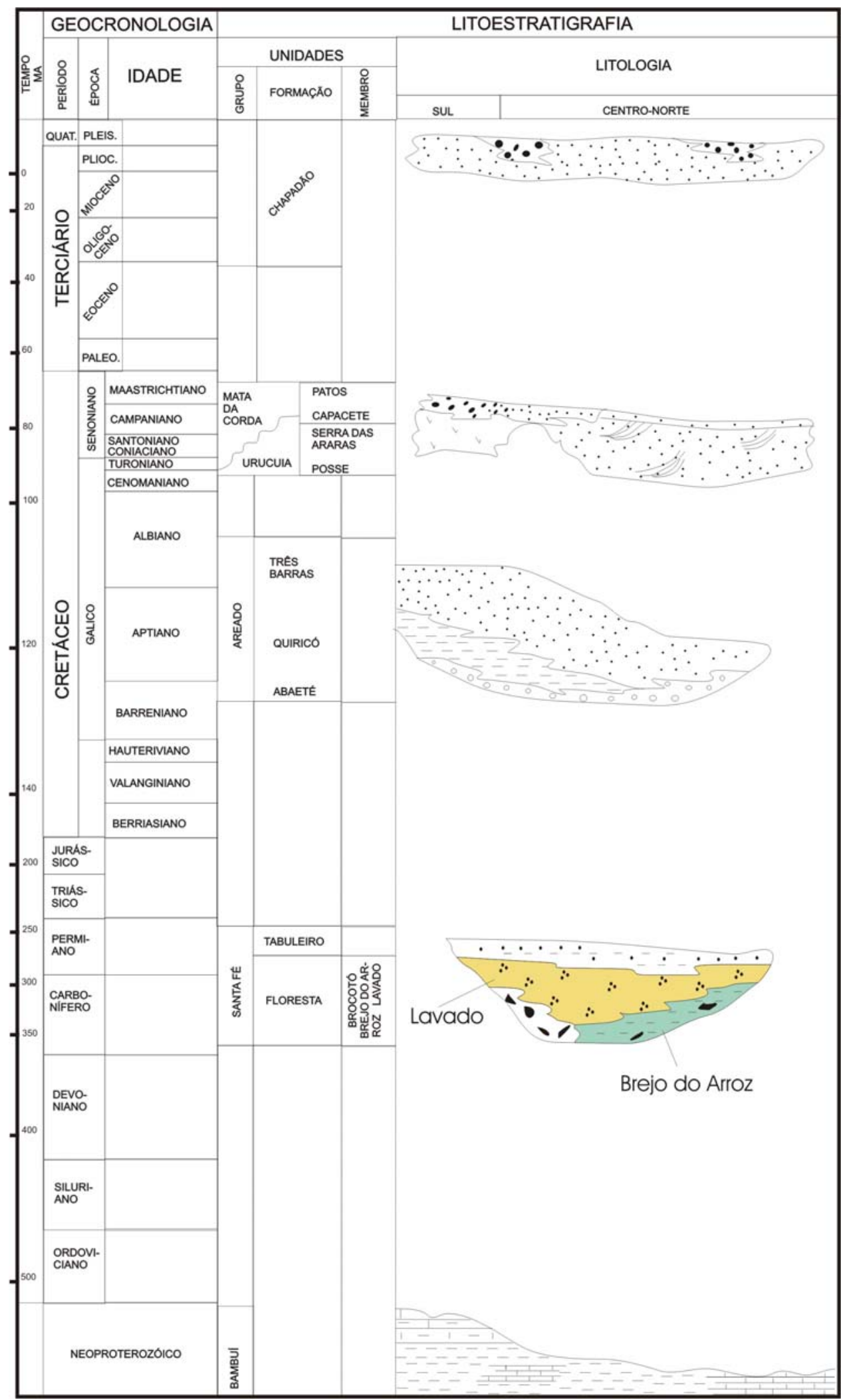

Figura 2.2. Estratigrafia simplificada da Bacia Sanfranciscana (Campos \& Dardenne,1997a). Em destaque os Membros Brejo do Arroz e Lavado. 


\subsubsection{Formação Floresta}

Os três membros Brocotó, Brejo do Arroz e Lavado foram englobados numa mesma formação por Campos \& Dardenne (1994), pois estes interdigitam-se lateralmente e verticalmente.

\subsubsection{Membro Brocotó}

O Membro Brocotó é constituído principalmente por diamictitos, com matriz síltico arenosa e de coloração avermelhada, que foram chamados de tilitos e tilóides (Campos \& Dardenne, 1994). Foram considerados verdadeiros tilitos os diamictitos maciços, não-estratificados, com clastos facetados e/ou estriados, enquanto que os diamictitos estratificados, com clastos mais arredondados foram denominados de tilóides. O Membro Brocotó ocorre na maioria dos casos sobre a Formação Três Marias, Grupo Bambuí.

Devido a uma granulometria extremamente variada, a presença de clastos facetados e às vezes estriados, o sistema deposicional está associado a resíduos de derretimento de capas de gelo. Os tilódes são o retrabalhamento dos tilitos por correntes aquosas.

\subsubsection{Membro Brejo do Arroz}

O Membro Brejo do Arroz geralmente se sobrepõe à Formação Três Marias (Campos \& Dardenne, 1994). É formado basicamente por folhelhos, siltitos e arenitos com ou sem seixos pingados, resultantes de um sistema deposicional glacio lacustre e turbidítico. Os seixos pingados são extremamente mal selecionados, com formas irregulares, angulosos e com uma face achatada às vezes estriada.

\subsubsection{Membro Lavado}

O Membro Lavado é constituído por arenitos vermelhos, ocorrendo também diamictitos com matriz arenosa, conglomerados finos e conglomerados intraformacionais. Os grãos detríticos apresentam em sua superfície uma película de 
óxidos, que dá a coloração vermelha. A deposição desta película ocorreu no início da diagênese, estes filmes de óxidos se depositaram não muito depois da sedimentação dos grãos (Campos \& Dardenne,1994).

O sistema deposicional associado a este membro é um sistema fluvio-glacial, devido a um fluxo entrelaçado de água proveniente do derretimento das capas de gelo.

\subsubsection{Formação Tabuleiro}

De acordo com Campos \& Dardenne (1994) a Formação Tabuleiro é constituída por arenitos homogêneos, vermelhos, rosados e localmente brancos com intercalações argilosas. Análises petrográficas feita por Campos \& Dardenne (1994) mostraram grãos de areia muito arredondados a esféricos, típicos de retrabalhamento eólico.

A Formação Tabuleiro recobre os três membros da Formação Floresta, inclusive a Formação Três Marias (Grupo Bambuí, embasamento local), apresentando distribuição mais ampla. O sistema deposicional associado é periglacial eólico-lacustre. Devido à passagem gradativa da Formação Floresta para Formação Tabuleiro, esta é considerada como sendo o registro do final da glaciação. 


\section{BASES FÍSICAS DO PALEOMAGNETISMO}

Neste capítulo serão introduzidos alguns conceitos físicos nos quais se baseia o Paleomagnetismo. As fontes de referência em que se baseia o texto são, principalmente, Tauxe (2002), Dunlop \& Özdemir (1997) e Butler (1992).

\subsection{O Campo Geomagnético}

O campo geomagnético é essencialmente um campo dipolar cujo eixo apresentase inclinado em relação ao eixo geográfico e deslocado em relação ao centro da Terra. Apresenta também uma componente não-dipolar. Em Paleomagnetismo introduz-se uma simplificação no modelo, considerando-se apenas um campo magnético geocêntrico e axial (DGA). Neste modelo o campo geomagnético é dado por um dipolo magnético simples, posicionado no centro da Terra e alinhado com o seu eixo de rotação. O ângulo de declinação (ângulo D em relação ao norte geográfico) é, portanto, nulo em todo o globo terrestre e a inclinação (ângulo Inc em relação à horizontal) varia com a latitude $(\lambda)$ conforme a Equação 3.1.

$$
\tan (\operatorname{Inc})=2 \tan (\lambda)
$$

A direção e a intensidade do campo geomagnético variam no tempo e as mudanças de longo período são denominadas variação secular. A variação secular devese tanto às variações de curto período do campo não dipolar quanto às variações de longo período do campo dipolar. Uma das componentes da variação secular, crucial para o Paleomagnetismo, é a deriva para oeste do campo dipolar. O dipolo principal descreve movimentos que resultam na migração dos pólos magnéticos (sul e norte) ao redor dos pólos geográficos com períodos da ordem de $7.000-10.000$ anos aproximadamente. A trajetória descrita é variável mas, em geral, os pólos não se afastam mais do que $30-40^{\circ}$ do pólo geográfico. Quando se faz a média das posições virtuais dos pólos magnéticos, em intervalos de tempo suficientemente longos, os pólos médios aproximam-se dos pólos geográficos. Esse resultado indica que a simplificação 
do modelo de dipolo geocêntrico axial (DGA) é perfeitamente admissível e não introduz erros grosseiros.

\subsection{O Registro Geomagnético nas Rochas}

Para que o registro do campo geomagnético seja preservado nas rochas, é necessário que a rocha contenha minerais magnéticos capazes de preservar a magnetização remanente por longos intervalos de tempo, isto é, centenas de milhões de anos e até alguns bilhões de anos.

$\mathrm{Na}$ natureza existem três tipos de minerais magnéticos: a) diamagnéticos adquirem magnetização em sentido contrário ao campo indutor e é removida em campo nulo; b) paramagnéticos - a magnetização induzida tem o mesmo sentido do campo indutor e é removida em campo nulo; c) ferromagnéticos - possuem átomos magnéticos que interagem fortemente entre si, resultando numa magnetização espontânea. Os minerais naturais deste último grupo, na realidade, classificam-se em ferrimagnéticos ou antiferromagnéticos.

Átomos magnéticos são aqueles que possuem um ou mais elétrons desemparelhados. Quando tais átomos são colocados lado a lado, a curtas distâncias, alinham-se de tal forma que a energia de troca entre eles torna-se mínima. Nos materiais antiferromagnéticos a disposição dos momentos magnéticos atômicos é antiparalela e de mesma intensidade, portanto a magnetização resultante é nula (Figura 3.1a). Nos ferrimagnéticos a disposição dos momentos magnéticos atômicos é antiparalela e de intensidades distintas (Figura 3.1b), logo existe magnetização espontânea, porém mais fraca que nos materiais ferromagnéticos cuja disposição dos momentos magnéticos atômicos é paralela (Figura 3.1c). 


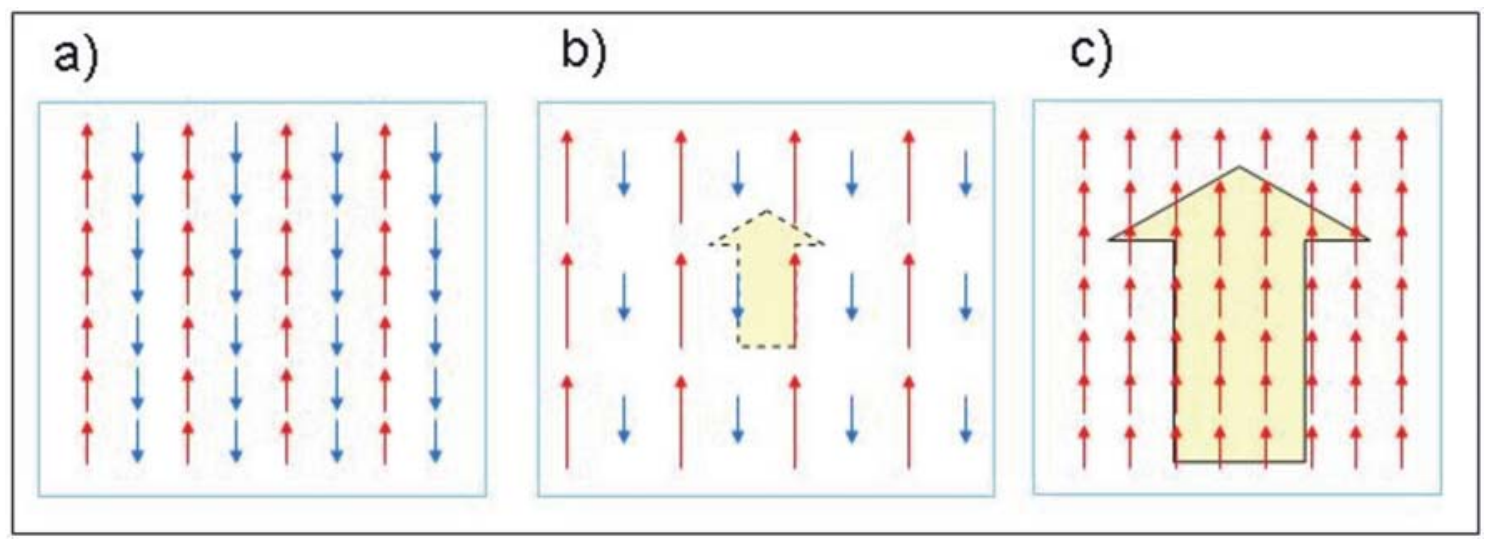

Figura 3.1. Ilustração da disposição dos momentos magnéticos atômicos nos três casos: a) antiferromagnético; b) ferrimagnético e c) ferromagnético.

A temperatura na qual a energia térmica se iguala à energia de interação magnética dos átomos (energia de troca) é chamada de temperatura de Néel $\left(T_{N}\right)$, no caso de materiais antiferromagnéticos, ou temperatura de Curie $\left(\mathrm{T}_{\mathrm{C}}\right)$, no caso de materiais ferromagnéticos e ferrimagnéticos. Acima dessa temperatura o comportamento passe a ser do tipo paramagnético. Isso ocorre porque a energia térmica, responsável pelo movimento aleatório dos momentos magnéticos, é maior que a energia de troca, responsável pelo alinhamento dos momentos.

$\mathrm{Na}$ natureza encontram-se apenas minerais do tipo ferrimagnético e antiferromagnético. A hematita $\left(\mathrm{Fe}_{2} \mathrm{O}_{3}\right)$ é um exemplo de mineral antiferromagnético, contudo este mineral possui magnetização espontânea à temperatura ambiente devido a uma inclinação entre os momentos atômicos.

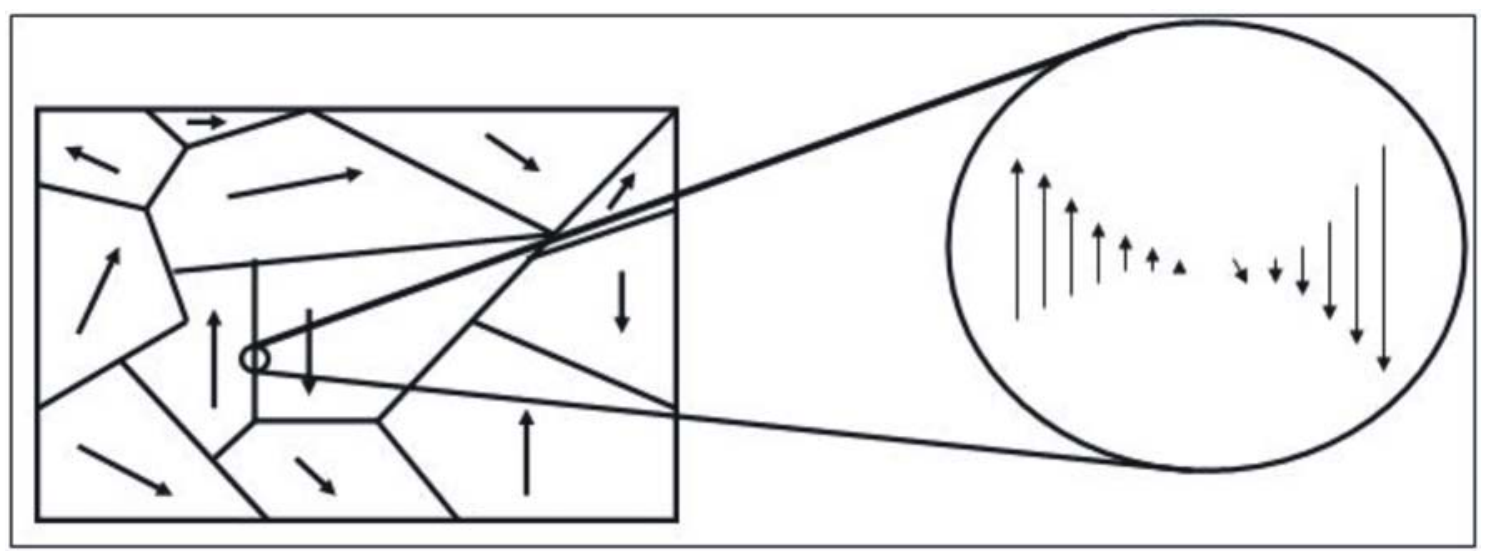

Figura 3.2. Ilustração dos domínios magnéticos de um material ferromagnético. 
Um material ferromagnético possui domínios magnéticos, os quais são separados por 'paredes' que são as zonas magneticamente 'fracas' (Figura 3.2). A transição de um domínio para outro é gradual, gerando orientações transicionais.

Um grão mineral pode ser multidomínio, monodomínio ou pseudomonodomínio, isto é, comportar-se como monodomínio mesmo tendo mais de um domínio. Um campo magnético aplicado a um grão multidomínio age nas paredes dos domínios deslocando-as de tal forma a aumentar a magnetização resultante. Quando o campo é retirado, as paredes não retornam exatamente para o mesmo lugar e o grão passa a ter uma remanência magnética, como mostra a ilustração da Figura 3.3. Esta propriedade, exclusiva do grupo de materiais ferromagnéticos, é chamada de histerese (Figura 3.4).

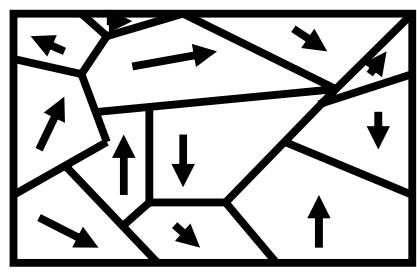

$H=0$ e $M=0$
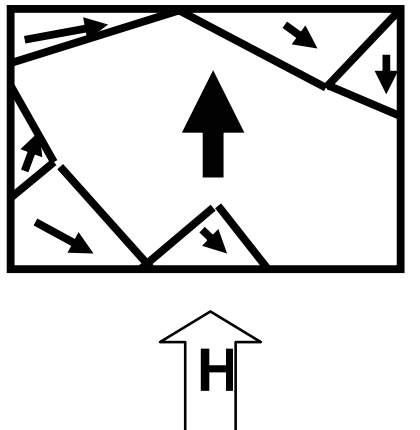

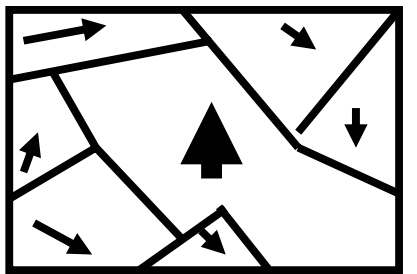

$\mathrm{H}=0$ e $\mathrm{M}=\mathrm{Mr}$

Figura 3.3. Ilustração da indução de magnetização em um grão multidominio.

Ao aplicar campos magnéticos crescentes com polaridade positiva, a um material ferromagnético com magnetização inicial nula, este material irá adquirir magnetização positiva até atingir a saturação (Ms). Ao diminuir a intensidade do campo aplicado a magnetização diminui, porém, quando o campo magnético aplicado se torna nulo, permanece uma magnetização chamada de magnetização remanente de saturação (Mrs). Se, no entanto, forem aplicados campos magnéticos com polaridade negativa, a magnetização remanente será eliminada para um campo de módulo Hc que corresponde à coercividade magnética do material. Hcr é o campo no qual a magnetização é anulada quando este é retirado, chamado de coercividade de remanência. Ao aumentar a 
intensidade do campo magnético negativo, a magnetização negativa também aumenta até atingir a saturação e quando este é retirado, resta a magnetização remanente de saturação negativa. O campo indutor se torna positivo como antes, remove a magnetização no ponto $\mathrm{Hc}$ e a magnetização aumenta até o ponto de saturação novamente. Estabelece-se assim um ciclo de histerese.

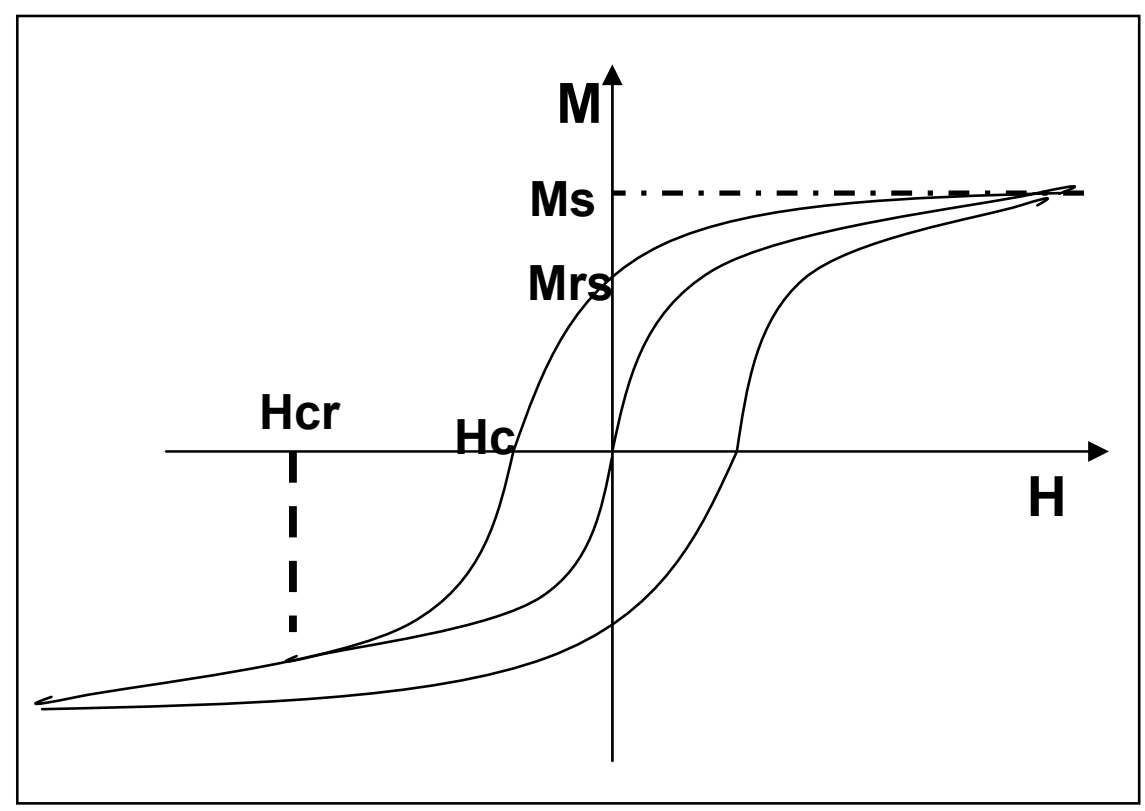

Figura 3.4. Curva de histerese onde $H$ é o campo magnético aplicado, $M$ é a magnetização adquirida, Ms é a magnetização de saturação, Mrs é a magnetização remanente de saturação, Hc é a coercividade e Hcr é a coercividade de remanência.

De acordo com Néel (1949 e 1955) a magnetização de um mineral decai exponencialmente com o tempo (Equação 3.2):

$$
M(t)=M_{0} e^{\left(\frac{-t}{\tau}\right)}
$$

onde $\mathrm{M}_{0}$ é a magnetização inicial e $\tau$ é o tempo de relaxação, tempo que leva para a magnetização diminuir de $\frac{1}{e}$. Quanto maior $\tau$, mais tempo levará para diminuir de $\frac{1}{e}$, portanto, quanto maior $\tau$ maior a estabilidade da magnetização. Para que um mineral possa preservar o registro do campo geomagnético por milhões de anos, deve 
ter $\tau$ da ordem de milhões a bilhões de anos. O tempo de relaxação depende do volume e da temperatura do grão, como mostra a Equação 3.3:

$$
\tau=\frac{1}{C} e^{\left(\frac{K v}{k T}\right)}
$$

Grãos com $\tau$ entre $10^{2}$ a $10^{3}$ segundos são grãos instáveis na escala de tempo de laboratório. A temperatura na qual $\tau$ situa-se entre $10^{2}$ a $10^{3}$ segundos é definida como temperatura de bloqueio $\left(\mathrm{T}_{\mathrm{b}}\right)$. Entre $\mathrm{T}_{\mathrm{b}}$ e $\mathrm{T}_{\mathrm{C}}\left(\right.$ ou $\left.\mathrm{T}_{\mathrm{N}}\right)$ o grão será superparamagnético, isto é, possui energia térmica suficiente para desalinhar os momentos magnéticos. Acima de $\mathrm{T}_{\mathrm{C}}\left(\right.$ ou $\left.\mathrm{T}_{\mathrm{N}}\right)$ será paramagnético.

\subsection{Principais Minerais Magnéticos}

Os principais minerais magnéticos encontrados na natureza são os óxidos de ferro e titânio e suas composições são convenientemente representadas em um diagrama ternário $\mathrm{TiO}_{2}-\mathrm{FeO}-\mathrm{Fe}_{2} \mathrm{O}_{3}$ (Figura 3.5). Posições da esquerda para a direita indicam crescimento da razão de $\mathrm{Fe}^{3+}$ para $\mathrm{Fe}^{2+}$ enquanto as posições da base para o topo indicam crescimento do conteúdo de titânio.

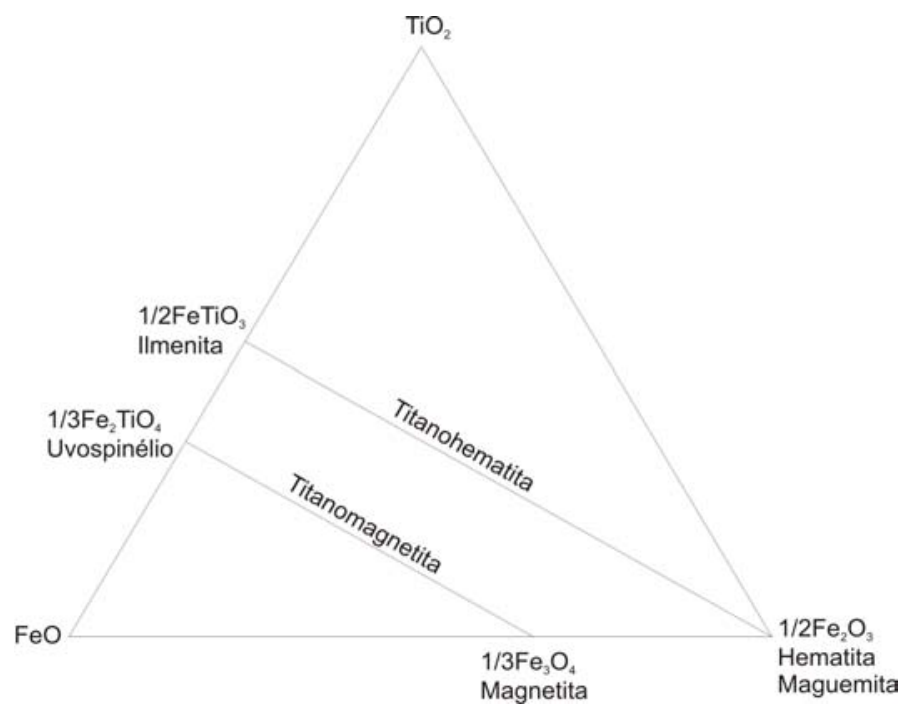

Figura 3.5. Diagrama ternário $\mathrm{TiO}_{2}-\mathrm{FeO}-\mathrm{Fe}_{2} \mathrm{O}_{3}$. Estão indicadas as composições de importantes minerais óxidos de ferro e titânio e as séries das soluções sólidas das titanomagnetitas e titanohematitas. 
A série das titanomagnetitas, que vai de magnetita ao uvospinélio é composta por minerais cúbicos com estrutura de espinélio inversa. A série das titanohematitas (também chamada de hemoilmenitas), é o equivalente oxidado das titanomagnetitas, todavia apresenta estrutura cristalina romboédrica.

A magnetita $\left(\mathrm{Fe}_{3} \mathrm{O}_{4}\right)$, possui temperatura de Curie de $580^{\circ} \mathrm{C}$, magnetização de saturação de $92 \mathrm{Am}^{2} \mathrm{~kg}^{-1}$ e coercividade de cerca de décimos de mT contra décimos de teslas da coercividade da hematita $\left(\alpha \mathrm{Fe}_{2} \mathrm{O}_{3}\right)$, que por sua vez possui temperatura de Néel de $680^{\circ} \mathrm{C}$ e magnetização de saturação de $0.4 \mathrm{Am}^{2} \mathrm{~kg}^{-1}$. Maghemita $\left(\gamma \mathrm{Fe}_{2} \mathrm{O}_{3}\right)$ é o mineral produzido pela oxidação da magnetita, o qual submetido a temperaturas entre $250-750^{\circ} \mathrm{C}$ se transforma em hematita $\left(\alpha \mathrm{Fe}_{2} \mathrm{O}_{3}\right)$. Devido a essa transformação a temperatura de Curie para a maghemita não é determinada com exatidão, variando entre 590-675 ${ }^{\circ}$ C. A TM60 (60\% de substituição de titânio - $\left.\mathrm{Fe}_{2.4} \mathrm{Ti}_{0.6} \mathrm{O}_{4}\right)$ é um exemplo da série das titanomagnetitas que possui temperatura de Curie de $150^{\circ} \mathrm{C}$ e magnetização de saturação de $24 \mathrm{Am}^{2} \mathrm{~kg}^{-1}$.

Outros exemplos de minerais magnéticos são os oxihidróxidos de ferro, como a goetita $(\alpha \mathrm{FeOOH})$ com temperatura de Néel de $70-125^{\circ} \mathrm{C}$ e os sulfetos de Ferro, como a pirrotita $\left(\mathrm{Fe}_{7} \mathrm{~S}_{8}\right)$ com temperatura de Curie de aproximadamente $325^{\circ} \mathrm{C}$ e a greigita $\left(\mathrm{Fe}_{3} \mathrm{~S}_{4}\right)$ com temperatura de desbloqueio de aproximadamente $330^{\circ} \mathrm{C}$.

\subsection{Magnetização Remanente}

Em rochas sedimentares a magnetização remanente é adquirida, primariamente pela deposição de grãos detríticos já magnetizados. Durante a deposição existe uma forte tendência de grãos magnéticos se tornarem alinhados ao campo geomagnético em resposta ao torque que este exerce no grão. Neste caso, a magnetização adquirida pela rocha em formação é denominada magnetização remanente deposicional (MRD). Na água existe a presença de movimentos turbulentos e agitação térmica que faz com que reste uma pequena parcela de grãos alinhados ao campo. Ao atingir a superfície de deposição o momento magnético do grão pode ser distorcido por ações gravitacionais. Essa distorção torna a inclinação da magnetização menor que a do campo aplicado, este fenômeno é conhecido como erro de inclinação, que é máximo em grãos com inclinações de $45^{\circ}$. Os grãos magnéticos podem ser deslocados por bioturbações, 
alinhados ao campo e novamente depositados. Neste caso a remanência é chamada de magnetização remanente detrítica pós deposicional (MRpD), onde a ação da gravidade não é significativa.

A rocha sedimentar também pode adquirir magnetização através de outros processos que resultam em magnetizações secundárias do tipo viscosa, térmica ou química.

Com o passar do tempo ocorre um aumento no número de grãos magnéticos que podem adquirir energia térmica suficiente para perder a orientação magnética original e se alinhar ao campo magnético presente. Quando isso ocorre o grão adquire uma nova magnetização, denominada magnetização remanente viscosa (MRV) e, em geral, afeta os grãos de mais baixa coercividade.

A magnetização térmica é adquirida quando uma rocha é aquecida. O mineral presente na rocha a uma temperatura acima de $T_{C}\left(\right.$ ou $\left.T_{N}\right)$ não possui magnetização e é paramagnético, com o esfriamento a uma temperatura entre $T_{C}\left(\right.$ ou $\left.T_{N}\right)$ e $T_{b}$ o mineral se torna superparamagnético e se alinha na direção do campo geomagnético. Quando a temperatura se torna inferior a $T_{b}$ o grão registra magnetização porque o seu tempo de relaxação alcança valores geologicamente significativos.

Como o tempo de relaxação é também fortemente relacionado com o volume do grão, para grãos muitos pequenos a energia térmica domina e o grão é superparamagnético. Com o crescimento do grão, a uma temperatura constante, o grão atinge um determinado volume, chamado volume de bloqueio, acima do qual o grão se torna ferromagnético e adquire uma magnetização. Essa magnetização é denominada de magnetização remanente química e pode ocorrer tanto em crescimento de novos grãos nos interstícios de rochas sedimentares como em alterações mineralógicas.

Uma rocha coletada em um dado contexto geológico possui remanência magnética que pode ter sido adquirida por uma variedade de mecanismos. A remanência desta rocha é a magnetização remanente natural (MRN), que pode ser primária, secundária ou a soma destas. Magnetização primária é a magnetização adquirida durante a formação da rocha e secundária é a magnetização adquirida depois da rocha formada. Quando a magnetização primária é totalmente removida e adquire outra dizemos que a rocha foi totalmente remagnetizada. 


\subsection{Métodos de Desmagnetização}

Para se determinar as componentes de magnetização presentes na rocha é necessário proceder-se a desmagnetizações. Neste trabalho foram utilizados dois procedimentos de desmagnetização: por campos magnéticos alternados e por temperaturas.

O ciclo de campo magnético alternado se inicia com intensidade máxima de campo magnético indutor e termina em zero. Ao aplicar um campo magnético alternado de intensidade máxima $\mathrm{H}$ a um espécime, os momentos magnéticos dos grãos com coercividade menor ou igual $\mathrm{H}$ irão se orientar na direção do campo aplicado. Ao se diminuir a zero a intensidade do campo aplicado, em ambiente de campo magnético nulo, os momentos magnéticos irão se orientar aleatoriamente e a magnetização resultante destes grãos será nula. Quanto maior a coercividade do mineral maior deve ser o campo magnético alternado aplicado para desmagnetizá-lo. A coercividade de um mineral varia com a composição, tamanho do grão e arranjo cristalino.

O procedimento de desmagnetização térmica consiste em aquecer os espécimes a uma determinada temperatura e esfriá-los na presença de um campo magnético nulo. Quando a temperatura de bloqueio de determinados grãos é atingida, estes se tornam superparamagnéticos e, por estarem na ausência de campo magnético externo, têm a sua magnetização removida. A cada etapa de desmagnetização térmica deve-se medir a susceptibilidade magnética volumétrica dos espécimes para controlar mudanças nas propriedades magnéticas devido a possíveis transformações mineralógicas.

\subsection{Análise das Componentes de Magnetização}

Projeções vetoriais ortogonais (Zijderveld, 1967) auxiliam na identificação das várias componentes de magnetização. As direções de remanência são calculadas utilizando a análise de componente principal de Kirschivink (1980), onde são dados pesos iguais aos pontos de uma seqüência que compõem uma única componente e a direção é calculada pelo método dos mínimos quadrados. 
Em Paleomagnetismo as direções médias são calculadas utilizando a estatística de Fisher (1953), que considera todos os $\mathrm{N}$ vetores de intensidade igual a um e a média das direções $<\vec{X}>$ igual à soma vetorial $(\vec{R})$ de todos os $\mathrm{N}$ vetores dividido pela sua intensidade $\mathrm{R}\left(<\vec{X}>=\frac{\vec{R}}{R}\right)$. Se $\mathrm{N}$ for próximo de $\mathrm{R}$ significa que as $\mathrm{N}$ direções são agrupadas (parâmetro k alto, $k=\frac{N-1}{N-R}$ ). Se a dispersão for muito grande, R será muito menor que $\mathrm{N}$, então o parâmetro $\mathrm{k}$ será baixo. Outro parâmetro levado em conta é o ângulo $\alpha_{95}\left(\alpha_{95} \approx \frac{140^{\circ}}{\sqrt{k N}}\right)$, que representa duas vezes o desvio padrão da média numa projeção esférica.

\subsection{Susceptibilidade Magnética}

Quando um campo magnético $(\vec{H})$ é aplicado em um material magneticamente isotrópico este adquire uma magnetização induzida $\left(\vec{M}_{i}\right)$ a qual varia conforme as propriedades do material. A relação entre campo aplicado $(\vec{H})$ e a magnetização induzida $\left(\vec{M}_{i}\right)$ é dada pela equação:

$$
\vec{H}=\chi \vec{M}_{i}
$$

A susceptibilidade magnética de um material $(\chi)$ varia com a temperatura. Ao aquecer um mineral que é ferrimagnético à temperatura ambiente, a susceptibilidade magnética aumenta ao atingir a temperatura de bloqueio, porque acima desta temperatura o mineral se torna superparamagnético, ou seja, os momentos magnéticos se alinham a qualquer direção de campo aplicado. Por outro lado quando a temperatura de Curie é atingida a susceptibilidade diminui drasticamente porque este se torna um mineral paramagnético. A curva termomagnética (susceptibilidade magnética versus temperatura) é um método muito utilizado para se saber quais os minerais magnéticos presentes na rocha em estudo.

$\mathrm{Na}$ natureza os materiais magnéticos anisotrópicos são os mais encontrados. $\mathrm{O}$ magnetismo por si só já é anisotrópico, não existem cargas isotrópicas magnéticas 
(como há na eletrostática); no magnetismo a menor unidade é um dipolo magnético que já possui direção e sentido. A anisotropia de um material magnético começa com a anisotropia atômica, o momento magnético de spin do elétron desemparelhado se alinha ao eixo perpendicular ao plano orbital do elétron. A anisotropia magnetocristalina é devida à disposição dos átomos magnéticos na rede cristalina, onde os átomos magnéticos interagem uns com os outros de tal forma a alinhar seus momentos magnéticos na posição de mínima energia. Além destes dois tipos de anisotropia um outro tipo que deve ser somado é a anisotropia de forma do grão, esta pode ser mais ou menos importante que a anisotropia magnetocristalina. Um grão alongado irá se magnetizar mais facilmente na direção do maior eixo do grão, devido a um campo contrário à magnetização, chamado de campo desmagnetizante, que tem maior intensidade nas direções dos eixos menores do grão e menor intensidade na direção do eixo maior. Este campo desmagnetizante resulta da própria magnetização do grão. Uma maneira de simplificar este problema é pensar que o campo desmagnetizante é ocasionado por cargas magnéticas positivas e negativas, dadas pela magnetização, distribuídas nas faces do grão perpendiculares a magnetização. Quanto maior a área da face, maior o número de cargas, maior o campo desmagnetizante (Figura 3.6).

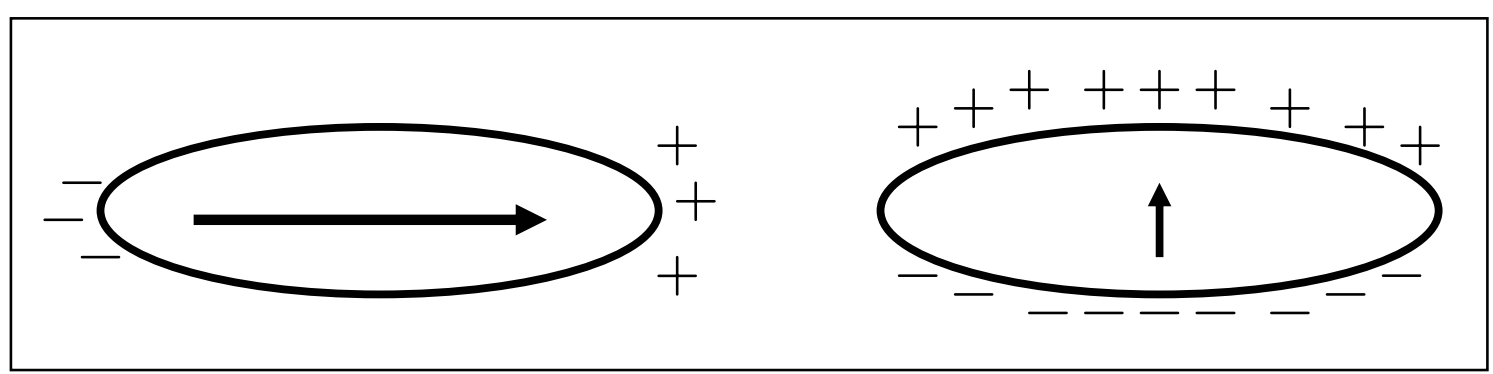

Figura 3.6. Ilustração da magnetização e cargas magnéticas positivas e negativas.

Quando um campo magnético $(\vec{H})$ é aplicado em um material magnético anisotrópico este adquire uma magnetização induzida $\left(\vec{M}_{i}\right)$ e a relação entre campo aplicado $(\vec{H})$ e a magnetização induzida $\left(\vec{M}_{i}\right)$ é dada pela equação:

$$
\vec{H}=[\chi] \vec{M}_{i}
$$


Como se vê na Equação 3.5 a susceptibilidade de um material anisotrópico é dada por um tensor, ou seja, a magnetização induzida não é necessariamente paralela ao campo aplicado. A anisotropia de susceptibilidade de um mineral anisotrópico é simplificada em um elipsóide cujos eixos são correspondentes aos valores de susceptibilidade maior, intermediária e menor dados por $\mathrm{K}_{1}, \mathrm{~K}_{2}$ e $\mathrm{K}_{3}$ respectivamente.

Normalmente os grãos magnéticos não esféricos possuem os eixos $\mathrm{K}_{1}, \mathrm{~K}_{2}$ e $\mathrm{K}_{3}$ de susceptibilidade paralelos aos seus eixos maior, médio e menor respectivamente. Quando medimos esta propriedade nas rochas podemos inferir a disposição dos grãos na rocha. Por exemplo, $\mathrm{K}_{1}$ alinhado a uma direção na rocha pode indicar que os grãos estão com seus eixos mais alongados nesta direção. A orientação espacial dos grãos é estatística e pode refletir processos geológicos tais como direção de paleocorrentes (no caso de rochas sedimentares) ou de fluxo de magma (no caso das rochas vulcânicas). 


\section{TRABALHO EXPERIMENTAL}

O trabalho experimental envolveu quatro principais etapas: amostragem, preparação de amostras, rotinas de laboratório para determinação da magnetização característica, mineralogia magnética e anisotropia de suscetibilidade magnética e análise de dados. O trabalho experimental foi inteiramente realizado no Laboratório de Paleomagnetismo do IAG/USP.

\subsection{Amostragem}

A amostragem do Grupo Santa Fé foi realizada no período de 28 de outubro a 5 de novembro de 2003, nas proximidades das cidades Santa Fé de Minas e Canabrava. As unidades de rochas amostradas foram os membros Brejo do Arroz e Lavado da Formação Floresta. Procurou-se amostrar o maior número de sítios (camadas) independentes possíveis mantendo bom controle estratigráfico dos mesmos. Sempre que possível utilizou-se amostrador portátil, retirando-se cilindros $(2.5 \mathrm{~cm}$ de diâmetro) orientados com bússola magnética ou solar. Quando não era possível, eram retirados blocos orientados.

Foram escolhidos dois pontos de amostragem do Membro Brejo do Arroz, localizados próximos a Canabrava e Santa Fé de Minas. No primeiro ponto (ponto 1, Figura 4.1) foram retirados 47 cilindros orientados, destes, dois foram retirados de dois seixos caídos e o restante foram retirados de 5 sítios ao longo de uma seção vertical de $0.6 \mathrm{~m}$ de espessura. No segundo ponto (ponto 2, Figura 4.1) foram amostrados 22 blocos orientados, incluindo um seixo caído; as amostras de mão foram retiradas de 6 sítios ao longo de uma seção vertical de $8 \mathrm{~m}$ de espessura. Neste caso a amostragem foi realizada na forma de blocos devido à fragilidade dos folhelhos. A amostragem dos seixos caídos foi realizada com o objetivo de verificar se as direções de magnetização dos seixos são aleatórias e distintas da encontrada na matriz, o que é esperado no caso de não ter sofrido nenhum evento intenso o suficiente para remagnetizar os seixos e a matriz. Estas seções de amostragem foram chamadas de Seção A do Brejo do Arroz (ponto 1) e Seção B do Brejo do Arroz (ponto 2). 


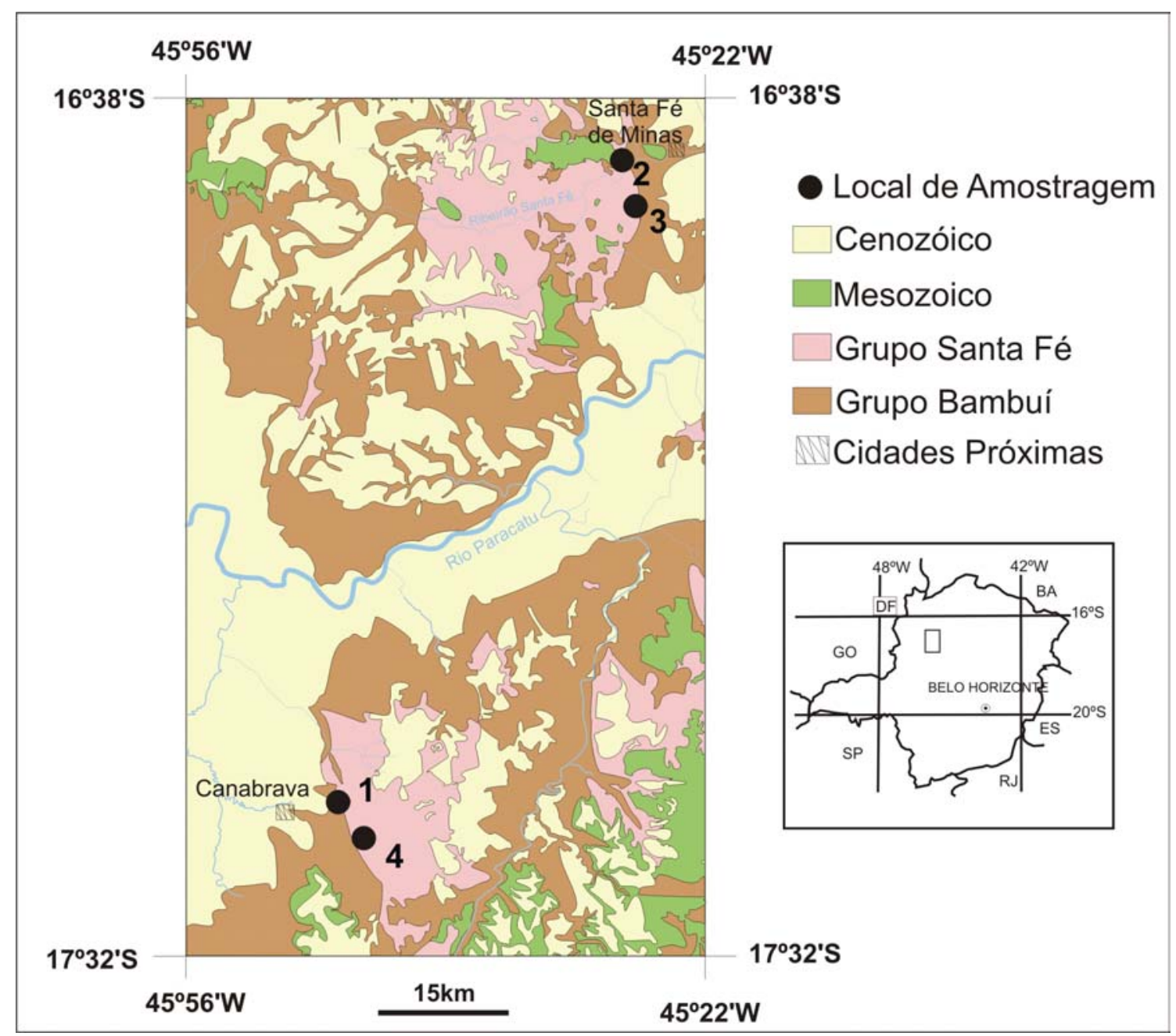

Figura 4.1. Mapa geológico e de localização da amostragem baseado em Projeto São Francisco - CPRM (2002).

Do Membro Lavado a amostragem foi realizada em duas localidades, uma nas proximidades do município de Santa Fé de Minas (ponto 3, Figura 4.1) e outra nas proximidades de Canabrava (ponto 4, Figura 4.1). No primeiro ponto de amostragem, que foi chamado de Seção A (ponto 3), foram retirados 98 cilindros orientados de 47 sítios ao longo de 3 subseções: duas paralelas e uma na porção superior, formando uma seção de aproximadamente $10 \mathrm{~m}$ de espessura Estas três subseções foram chamadas de A1 (sítios 40 a 55), A2 (sítios 56 a 63) e A3 (sítios 64 a 86). A posição relativa dos sítios amostrados está indicada na Figura 4.2. No outro ponto, que foi chamado de Seção B (ponto 4), foram retirados 58 cilindros de 18 sítios ao longo de uma seção vertical de cerca de $10 \mathrm{~m}$ de espessura. 


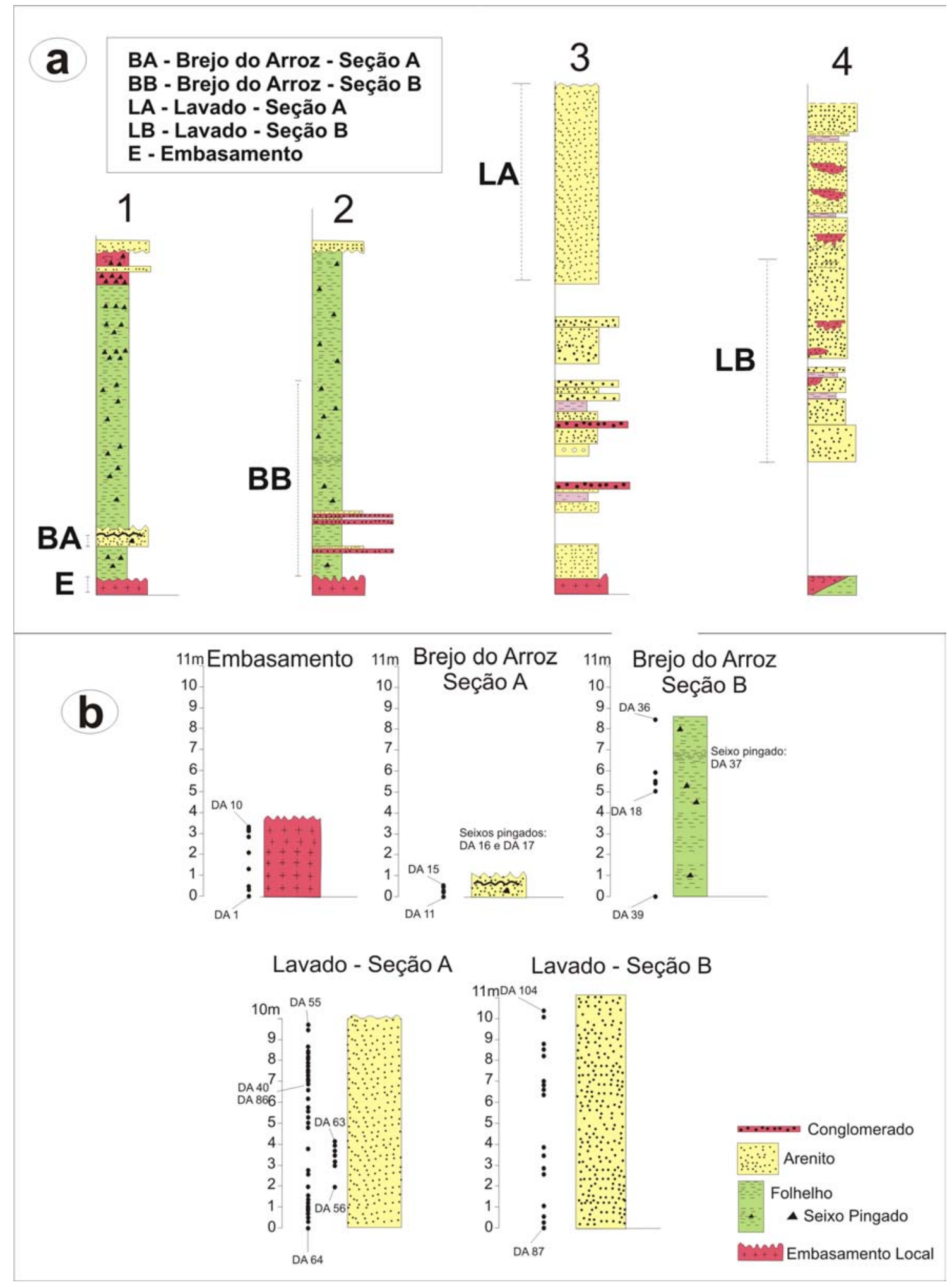

Figura 4.2. a) Colunas estratigráficas referentes às seções estudadas (Rocha-Campos, dados não publicados); b) Detalhe das mesmas seções, posicionando as amostras coletadas. 
Foram amostrados também dez sítios ao logo de uma seção de $3 \mathrm{~m}$ de espessura (40 cilindros orientados) do embasamento local (Grupo Bambuí, ponto de amostragem 1 na Figura 4.1) com a finalidade de testar possível remagnetização geral da área de estudo.

Estas seções são melhores compreendidas visualizando a Figura 4.2 onde estão os tipos de rochas encontrados nas seções e a distribuição dos sítios na estratigrafia.

\subsection{Preparação de Amostras}

Duas técnicas de preparação de amostras foram utilizadas, uma com os cilindros e outra com os blocos. A preparação das amostras cilíndricas consiste em cortá-las em espécimes cilíndricos menores de $2.2 \mathrm{~cm}$ de altura. De cada cilindro orientado foi possível se obter de um a quatro espécimes. A marcação de orientação do cilindro foi propagada para os demais espécimes. Esta marcação foi feita com tinta nanquim para que, durante a etapa de aquecimento dos espécimes (em laboratório), essa marcação não fosse removida, já que com tinta de caneta essa marcação se apaga nos primeiros passos de aquecimento. Foram preparados ao todo 466 espécimes cilíndricos.

A técnica de preparação dos blocos se iniciou com a propagação da marcação de orientação para todo o topo do bloco, utilizando linhas paralelas. Para muitos blocos não se pôde utilizar a furadeira de bancada para se retirar cilindros porque os blocos eram muito frágeis. Por isso estes foram nivelados em gesso e cortados em pequenos cubos de volume aproximadamente igual aos espécimes cilíndricos. Ao todo foram preparados 125 espécimes cúbicos.

\subsection{Trabalho Experimental}

Para se determinar o vetor de magnetização remanente e as componentes que o compõem foi necessário fazer a desmagnetização gradual dos espécimes, medindo a magnetização remanente a cada etapa de desmagnetização. Os dois procedimentos de desmagnetização utilizados neste trabalho foram a desmagnetização por campos magnéticos alternados (c.a.) e desmagnetização térmica. Estes dois procedimentos 
foram realizados dentro de uma sala magneticamente blindada para que, durante os procedimentos realizados, não houvesse remagnetização residual dos espécimes.

Mediu-se também a anisotropia de susceptibilidade magnética (ASM) dos espécimes, o que foi feito antes de submetê-los a qualquer procedimento de desmagnetização, para evitar os efeitos de possíveis transformações mineralógicas ou modificações da estrutura de domínios magnéticos.

\subsubsection{Anisotropia de susceptibilidade magnética}

Mediu-se a anisotropia de suscetibilidade magnética de todos os espécimes em equipamento da Molspin Ltd. Em muitos espécimes a susceptibilidade e o grau de anisotropia eram muito baixos e ficaram dentro da faixa de ruído do equipamento. Por essa razão muitos sítios (33\%) apresentaram resultados muito dispersos e calcular os tensores de anisotropia de susceptibilidade médios para estes sítios mostrou-se impossível. Este tipo de comportamento está ilustrado na Figuras 4.3A, que mostra a projeção estereográfica para as direções de susceptibilidade magnética máxima $\left(\mathrm{K}_{1}\right)$, intermediária $\left(\mathrm{K}_{2}\right)$ e mínima $\left(\mathrm{K}_{3}\right)$.

Em 23\% dos sítios os eixos de maior susceptibilidade $\left(\mathrm{K}_{1}\right)$ e de susceptibilidade intermediário $\left(\mathrm{K}_{2}\right)$ se distribuíram em baixas inclinações sem direções preferenciais (Figura 4.3B), indicando comportamento característico de ambientes deposicionais de baixa energia. Em $31 \%$ dos sítios os eixos de maior susceptibilidade $\left(\mathrm{K}_{1}\right)$ apresentaram direções mais bem definidas e de baixas inclinações (Figuras 4.3C) e que podem ser indicativas de paleo-correntes ou outros processos a serem investigados.

Para $13 \%$ dos sítios, entretanto, foram encontradas direções de $K_{1}$ com inclinações altas como mostra a Figuras 4.3D. Para um ambiente deposicional esse não é um comportamento esperado, entretanto num ambiente glacial onde se desenvolveram estrias do pavimento, ou as perturbações causadas pelos seixos pingados, é possível que localmente tenha havido movimentação dos sedimentos. 

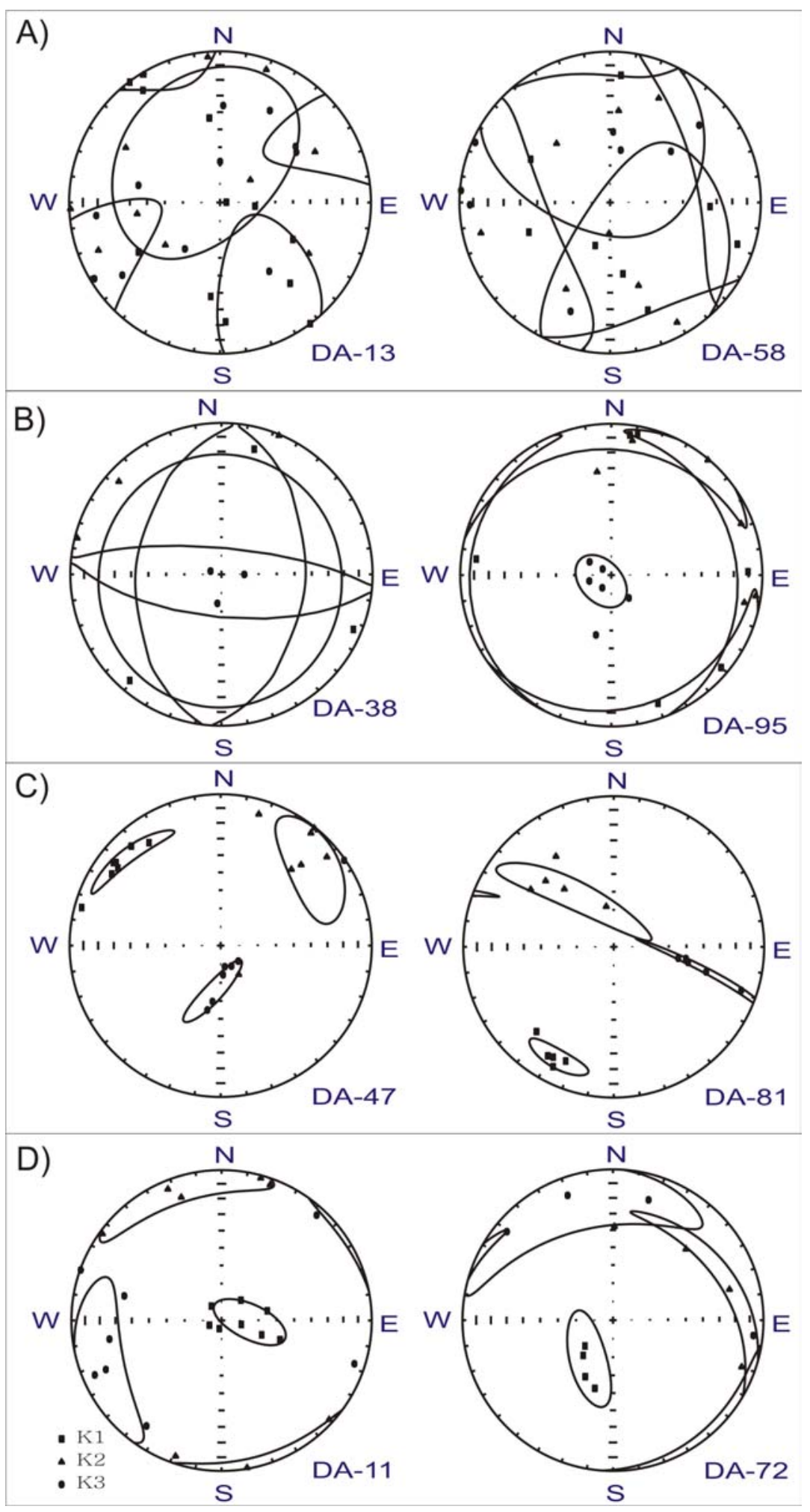

Figura 4.3. Exemplos de dados de anisotropia de susceptibilidade magnética em projeções estereográficas de inclinação positiva. A) exemplos com muita dispersão nos dados; B) exemplos com distribuição dos eixos K1 e K2 no plano de acamamento; C) Exemplos com distribuição dos eixos de maior susceptibilidade no plano de acamamento com a indicação de uma direção preferencial e D) Exemplos com distribuição dos eixos de maior susceptibilidade com altas inclinações. 
Apenas para os sítios com direções de $\mathrm{K}_{1}, \mathrm{~K}_{2}$ e $\mathrm{K}_{3}$ mais agrupadas, ou seja, que mostravam um lineamento, foram calculadas médias dos tensores de anisotropia utilizando o método de Lienert (1992). A Tabela 4.1 mostra as médias de $\mathrm{K}_{1}$ para cada sítio, os valores dos coeficientes de grau de anisotropia (P), lineação (L) e foliação (F).

Tabela 4.1. Dados médios de anisotropia magnética para os sítios com lineação.

\begin{tabular}{|c|c|c|c|c|c|c|c|c|c|c|}
\hline sítio & Dec K1 $\left({ }^{\circ}\right)$ & $\operatorname{Erro}\left({ }^{\circ}\right)$ & Inc K1 $\left({ }^{\circ}\right)$ & $\operatorname{Erro}\left({ }^{\circ}\right)$ & $\mathbf{P}$ & erro $P$ & $\mathbf{L}$ & Erro L & $\mathbf{F}$ & erroF \\
\hline 12 & 297.6 & 45 & 13.2 & 14 & 1.05 & 0.006 & 1.033 & 0.009 & 1.017 & 0.009 \\
\hline 15 & 20.6 & 45 & 24.4 & 20 & 1.163 & 0.015 & 1.018 & 0.022 & 1.143 & 0.045 \\
\hline 27 & 42.1 & 60 & 11.1 & 37 & 1.058 & 0.009 & 1.015 & 0.011 & 1.042 & 0.010 \\
\hline 41 & 294.7 & 39 & 5.2 & 20 & 1.035 & 0.003 & 1.029 & 0.004 & 1.006 & 0.005 \\
\hline 42 & 102.9 & 45 & 15.1 & 25 & 1.082 & 0.013 & 1.056 & 0.017 & 1.016 & 0.019 \\
\hline 43 & 281.8 & 42 & 21.5 & 15 & 1.045 & 0.004 & 1.028 & 0.005 & 1.016 & 0.007 \\
\hline 45 & 274.3 & 32 & 4.5 & 15 & 1.031 & 0.003 & 1.016 & 0.003 & 1.015 & 0.004 \\
\hline 57 & 117.3 & 22 & 52 & 11 & 1.048 & 0.006 & 1.037 & 0.006 & 1.01 & 0.006 \\
\hline 59 & 158.6 & 23 & 47.5 & 8 & 1.109 & 0.029 & 1.076 & 0.031 & 1.031 & 0.023 \\
\hline 60 & 206.2 & 11 & 64.1 & 7 & 1.137 & 0.021 & 1.095 & 0.025 & 1.038 & 0.019 \\
\hline 61 & 259.1 & 16 & 52.3 & 8 & 1.207 & 0.040 & 1.192 & 0.048 & 1.013 & 0.031 \\
\hline 63 & 319.6 & 25 & 7.2 & 16 & 1.164 & 0.018 & 1.063 & 0.019 & 1.096 & 0.030 \\
\hline 64 & 323.2 & 22 & 5.3 & 16 & 1.057 & 0.002 & 1.033 & 0.007 & 1.024 & 0.011 \\
\hline 68 & 324 & 81 & 25.1 & 44 & 1.109 & 0.018 & 1.044 & 0.019 & 1.062 & 0.030 \\
\hline 72 & 211.9 & 27 & 64.5 & 10 & 1.138 & 0.023 & 1.081 & 0.026 & 1.052 & 0.040 \\
\hline 73 & 162.3 & 67 & 46.4 & 29 & 1.082 & 0.010 & 1.034 & 0.011 & 1.046 & 0.015 \\
\hline 75 & 307.1 & 75 & 28.8 & 7 & 1.119 & 0.037 & 1.056 & 0.034 & 1.06 & 0.039 \\
\hline 77 & 190.4 & 65 & 26.1 & 3 & 1.071 & 0.003 & 1.034 & 0.007 & 1.036 & 0.007 \\
\hline 78 & 154 & 53 & 28.5 & 27 & 1.055 & 0.014 & 1.047 & 0.019 & 1.008 & 0.013 \\
\hline 79 & 63.4 & 39 & 8 & 8 & 1.058 & 0.005 & 1.035 & 0.006 & 1.023 & 0.005 \\
\hline 81 & 206.7 & 15 & 17.7 & 6 & 1.089 & 0.019 & 1.047 & 0.018 & 1.04 & 0.017 \\
\hline 82 & 128.2 & 44 & 29.6 & 27 & 1.057 & 0.005 & 1.024 & 0.007 & 1.032 & 0.005 \\
\hline 84 & 326.6 & 43 & 29.6 & 14 & 1.015 & 0.003 & 1.011 & 0.003 & 1.005 & 0.004 \\
\hline 89 & 157.5 & 33 & 8.4 & 9 & 1.101 & 0.006 & 1.026 & 0.008 & 1.073 & 0.011 \\
\hline 91 & 66.5 & 33 & 30.8 & 22 & 1.153 & 0.033 & 1.089 & 0.036 & 1.059 & 0.026 \\
\hline 93 & 74.7 & 67 & 3.8 & 35 & 1.066 & 0.005 & 1.026 & 0.005 & 1.039 & 0.009 \\
\hline 99 & 271.7 & 33 & 52.6 & 13 & 1.264 & 0.018 & 1.117 & 0.016 & 1.131 & 0.030 \\
\hline 104 & 86.3 & 40 & 11 & 10 & 1.182 & 0.021 & 1.072 & 0.019 & 1.102 & 0.051 \\
\hline
\end{tabular}

Declinação (Dec), inclinação (Inc) médias de K1; grau de anisotropia (P); lineação (L); foliação (F) 
Para a maioria dos sítios os eixos de maior susceptibilidade se distribuíram ou se agruparam no plano do acamamento, ou seja, a disposição dos grãos é ao longo do plano do acamamento, o que é esperado em uma rocha sedimentar sem alterações.

A distribuição de $\mathrm{K}_{1}$ médios ficou em maioria na direção SE-NW como mostra a Figura 4.4, na qual estão mostradas as direções de $\mathrm{K}_{1}$ médios numa projeção estereográfica.

Apenas $20 \%$ do total de sítios possuem valores de grau de anisotropia ( $\mathrm{P}=$ $\mathrm{K}_{1} / \mathrm{K}_{3}$ ) acima de 1.10 , ou seja, $\mathrm{K}_{1} 10 \%$ maior que $\mathrm{K}_{3}$, os quais foram considerados sítios com anisotropia.

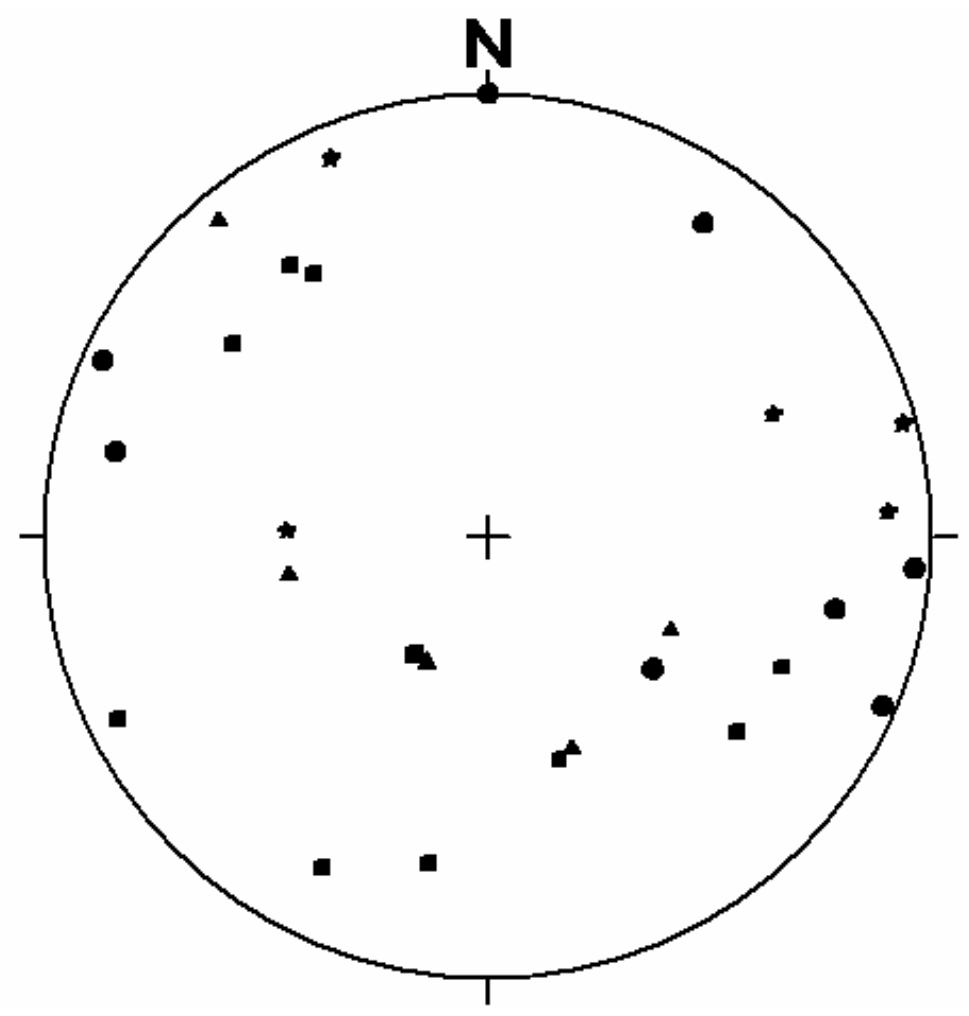

Figura 4.4. Projeção estereográfica das direções médias de K1: círculos, triângulos e quadrados representam, respectivamente, as seções A1, A2 e A3 do Membro Lavado e as estrelas, a seção B do Membro Lavado.

\subsubsection{Desmagnetização por campos magnéticos alternados}

As desmagnetizações por campos magnéticos alternados (c.a.) foram efetuadas em equipamento automático da $2 \mathrm{G}$ Enterprises acoplado ao magnetômetro criogênico onde foram medidas as magnetizações. Primeiramente foi escolhido um espécime de 
cada sítio para se fazer a desmagnetização, chamados de amostras-piloto. Este primeiro ensaio com as amostras-piloto é realizado para se conhecer as coercividades e temperaturas de bloqueio características do grupo de espécimes. Foram escolhidas 89 amostras-piloto dos 89 sítios, destes 10 são do embasamento, 3 dos seixos pingados e 76 do Grupo Santa Fé. Foi feita a desmagnetização c.a. para as 89 amostras-piloto de zero a $160 \mathrm{mT}$ em passos de no mínimo $2.5 \mathrm{mT}$ e no máximo $20 \mathrm{mT}$.

O que se observou em todos os espécimes é que a intensidade de magnetização não foi totalmente removida com a desmagnetização c.a. (como mostra a Figura 4.5A) e por isso foi necessária a desmagnetização térmica destas. Conclui-se a partir destes dados que estes espécimes possuem, como portadores de remanência, minerais com baixa coercividade, responsáveis pela porção da magnetização removida, e minerais com alta coercividade, responsáveis pela porção da magnetização não removida.

\subsubsection{Desmagnetização térmica}

A desmagnetização térmica das amostras-piloto foi realizada em passos de no mínimo $20^{\circ} \mathrm{C}$ e no máximo $50^{\circ} \mathrm{C}$, iniciando-se a $150^{\circ} \mathrm{C}$ e terminando a $680^{\circ} \mathrm{C}$. A cada etapa foi medida a susceptibilidade magnética volumétrica dos espécimes para controlar mudanças nas propriedades magnéticas devido a possíveis transformações mineralógicas.

Para todos os espécimes a magnetização remanente foi totalmente removida na temperatura de $680^{\circ} \mathrm{C}$. Para alguns espécimes houve uma queda anterior na intensidade de magnetização em temperaturas entre $580^{\circ} \mathrm{C}$ e $620^{\circ} \mathrm{C}$. A Figura $4.5 \mathrm{~B}$ exemplifica este comportamento. 


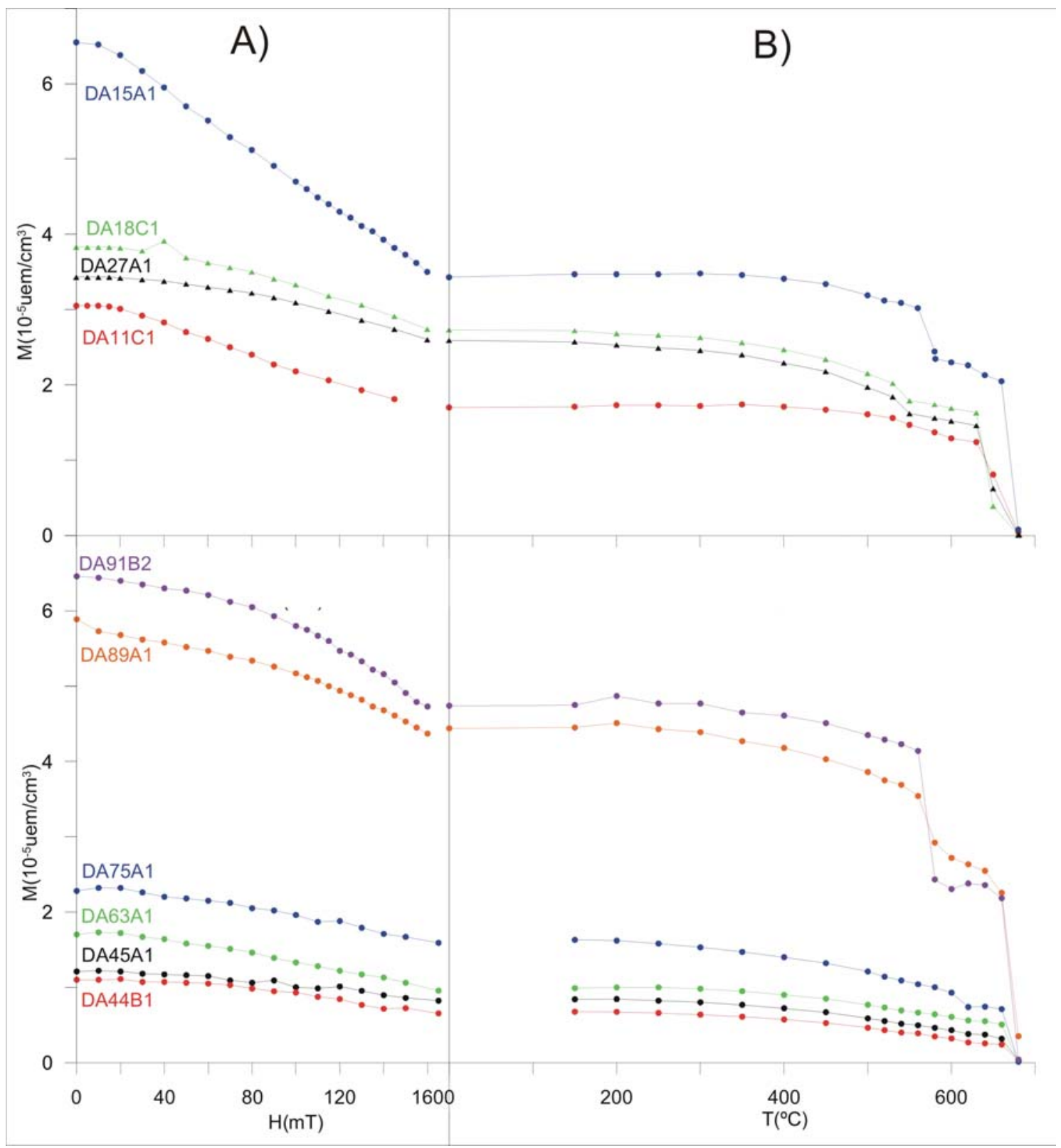

Figura 4.5. Variação da intensidade de exemplos de amostras-piloto que passaram pelo procedimento detalhado de demagnetização c.a. (A) e térmico (B). Na parte superior amostras do Membro Brejo do Arroz e na inferior amostras do Membro Lavado. Círculos são dados de arenitos e triângulos de folhelhos.

O fato de existir as duas quedas na remanência indica a presença de dois portadores de remanência distintos. Sendo provável a presença da hematita em todos os espécimes (remoção total a $680^{\circ} \mathrm{C}$ ) e em alguns a presença da magnetita (queda de intensidade em temperaturas entre $580^{\circ} \mathrm{C}$ e $620^{\circ} \mathrm{C}$ ). 


\subsection{Determinação das Componentes de Magnetização}

Para a determinação das direções de magnetização presentes nos espécimes foi utilizado o método de ajuste por mínimos quadrados de Kirschvink (1980). Foi verificada a presença de uma única componente de magnetização na maioria dos espécimes analisados, alguns tinham uma direção secundária que foi removida nos primeiros passos de desmagnetização c.a. As Figuras 4.9 e 4.10 mostram projeções vetoriais de alguns espécimes, pela distribuição dos pontos pode-se observar, grosseiramente, este comportamento unidirecional.

Considerando que a desmagnetização térmica é um procedimento lento e que pode produzir alterações químico-mineralógicas nos espécimes, procurou-se avaliar a necessidade de se efetuar a desmagnetização térmica em todos os demais espécimes. Para tanto foi feita a comparação entre as médias dos vetores de magnetização identificados entre $10-160 \mathrm{mT}$ e dos vetores identificados entre $150-680^{\circ} \mathrm{C}$ para as amostras-piloto inicialmente analisadas.

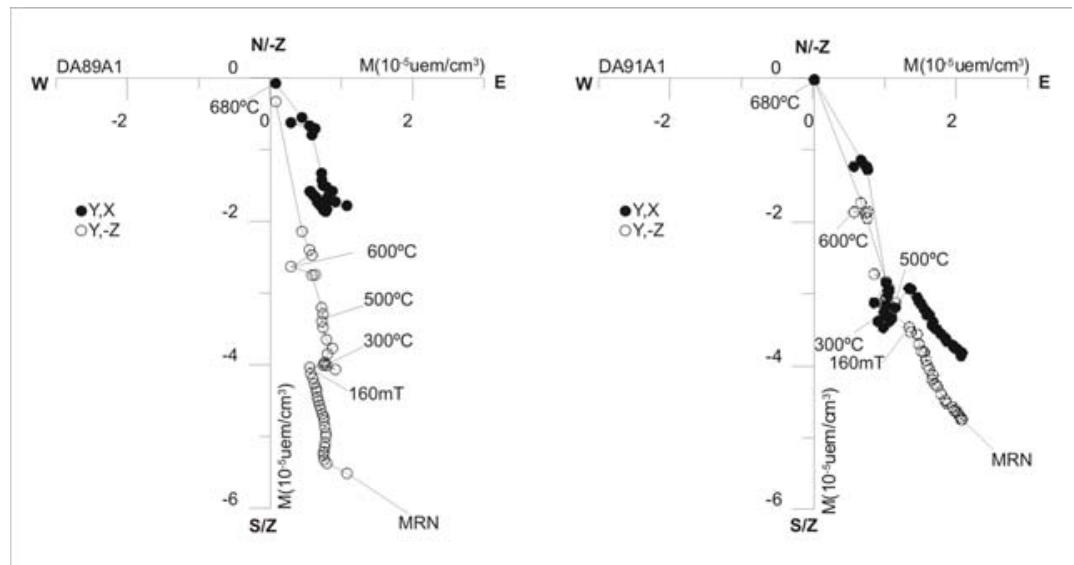

Figura 4.9. Projeções vetoriais e estereográficas de exemplos de amostras-piloto do Membro Lavado que passaram pelo procedimento detalhado de desmagnetização c.a. e térmica. 


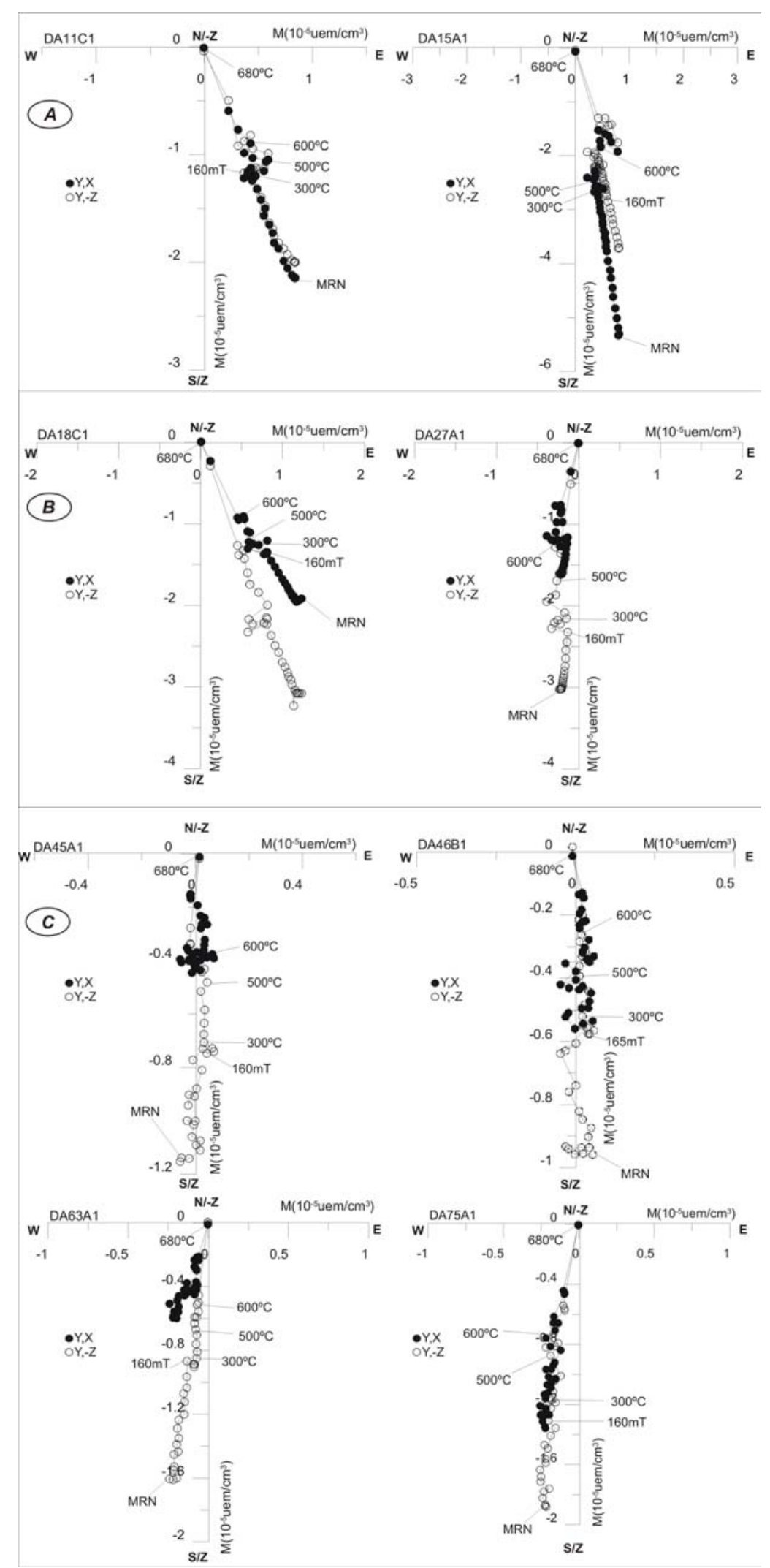

Figura 4.10. Projeções vetoriais de exemplos de amostras-piloto que passaram pelo procedimento detalhado de desmagnetização c.a. e térmica. Em A e B são exemplos do Membro Brejo do Arroz e C são do Membro Lavado. 


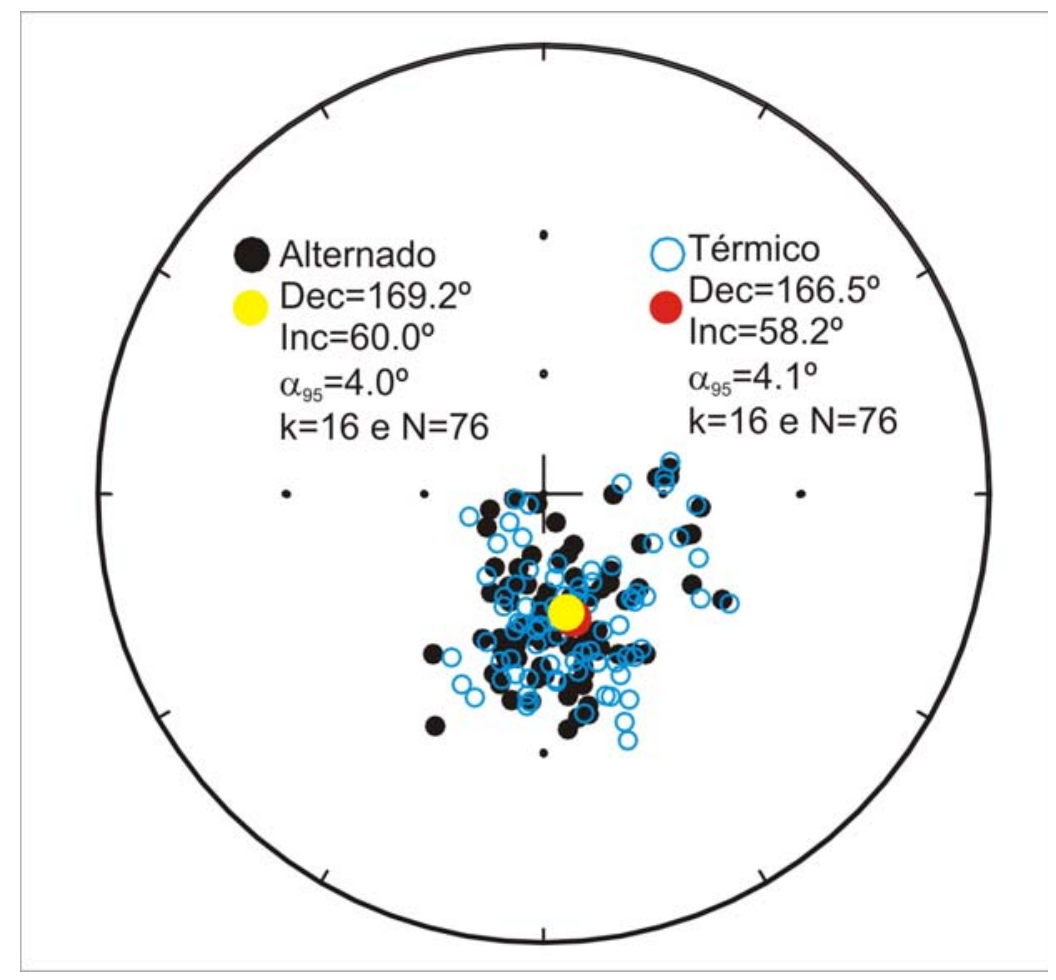

Figura 4.11. Distribuição das direções encontradas para o sedimento do Grupo Santa Fé com a desmagnetização por campos alternados (em preto) e das direções encontradas com a desmagnetização térmica (azul sem preenchimento). Comparação entre as médias dos dois grupos de direções: amarelo para desmagnetização c.a. e vermelho para desmagnetização térmica. Os círculos são proporcionais ao parâmetro de confiança de $95 \%\left(\alpha_{95}\right)$.

A Figura 4.11 mostra as distribuições das direções e os dois valores médios em uma projeção estereográfica. As direções médias calculadas para os dois grupos são iguais dentro do erro estatístico. Desta forma concluiu-se que tanto os minerais com baixa coercividade como os de alta coercividade, estatisticamente são portadores da mesma direção de magnetização e, portanto, fazendo a desmagnetização c.a. para os espécimes restantes seria suficiente para determinar a direção característica dos espécimes. Foi feita a desmagnetização c.a. para complementar 3 espécimes por sítio e a desmagnetização térmica de mais um conjunto de espécimes complementar.

\subsection{Caracterização da Mineralogia Magnética}

Os procedimentos de desmagnetização revelaram claramente a presença de hematita como principal mineral portador da magnetização, e secundariamente presença 
de magnetita. Ainda assim, alguns experimentos foram realizados para melhor caracterizar a ocorrência desses minerais.

\subsubsection{Aquisição de magnetização induzida e teste de Lowrie}

Foi feita a aquisição de magnetização remanente induzida (MRI) em campos magnéticos de até $2.8 \mathrm{~T}$ com seis amostras que passaram pela desmagnetização por campos alternados. Os resultados estão mostrados na Figura 4.6.
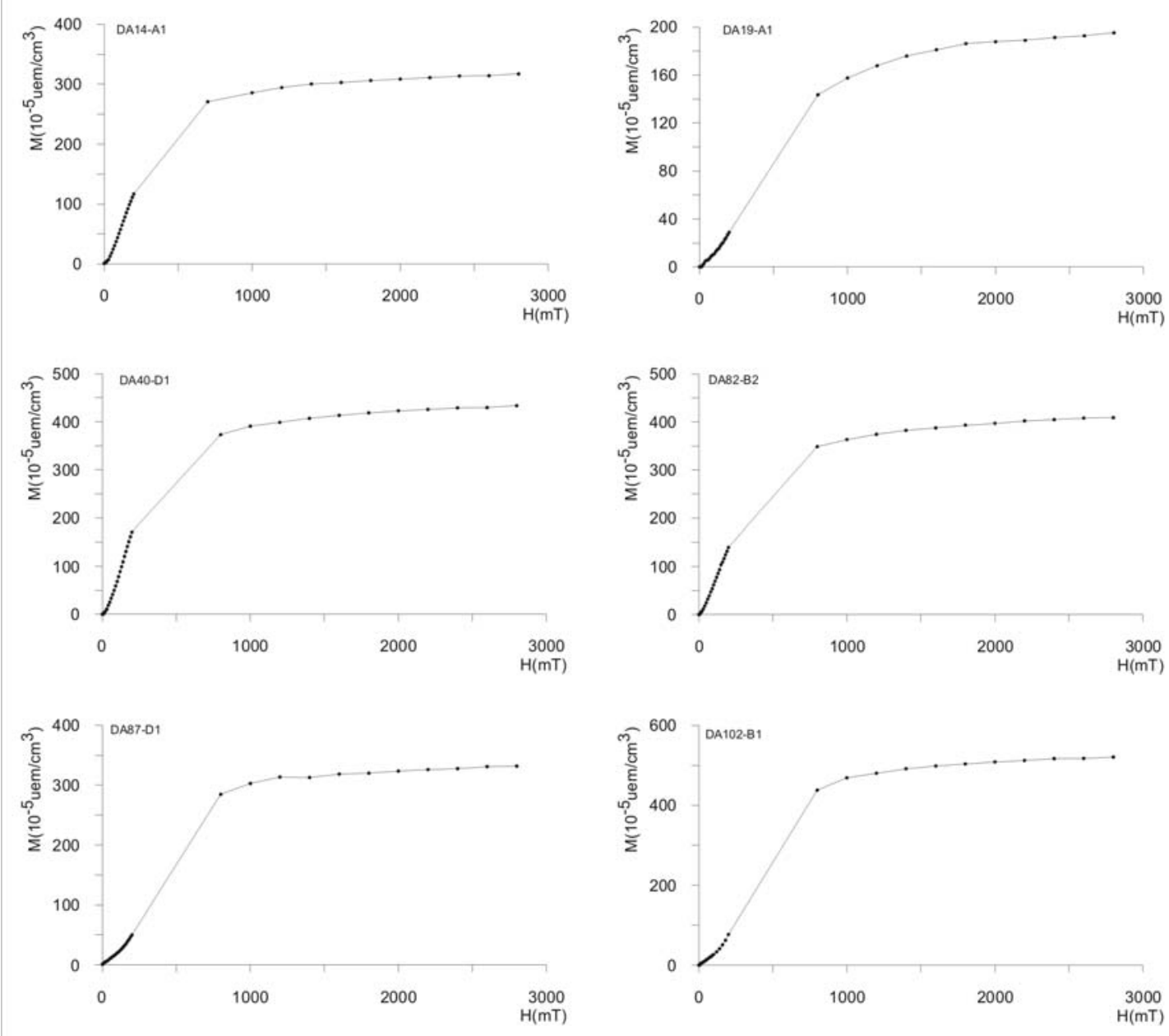

Figura 4.6. Curvas de aquisição de magnetização induzida.

Observa-se na Figura 4.6 que as amostras trabalhadas não atingiram o ponto de saturação, exibindo um comportamento de um mineral magnético muito coercivo como a hematita, nas amostras DA-14, 40 e 82 os passos de indução entre zero e $200 \mathrm{mT}$ 
resultou em uma maior intensidade de magnetização, portanto a concentração de minerais de menor coercividade é mais significativa nestas amostras.

Com as amostras que passaram pelo procedimento de indução foi feito o teste de Lowrie (1990) o qual consiste em induzir magnetização de intensidade alta, média e baixa nos três eixos perpendiculares dos espécimes e depois proceder-se a desmagnetização térmica. Neste caso foi feita a indução de $2.8 \mathrm{~T}$ no eixo $\mathrm{z}$ dos espécimes, 200mT no eixo x dos espécimes e 50mT no eixo y dos espécimes. As curvas de desmagnetização das amostras estão representadas na Figura 4.7.

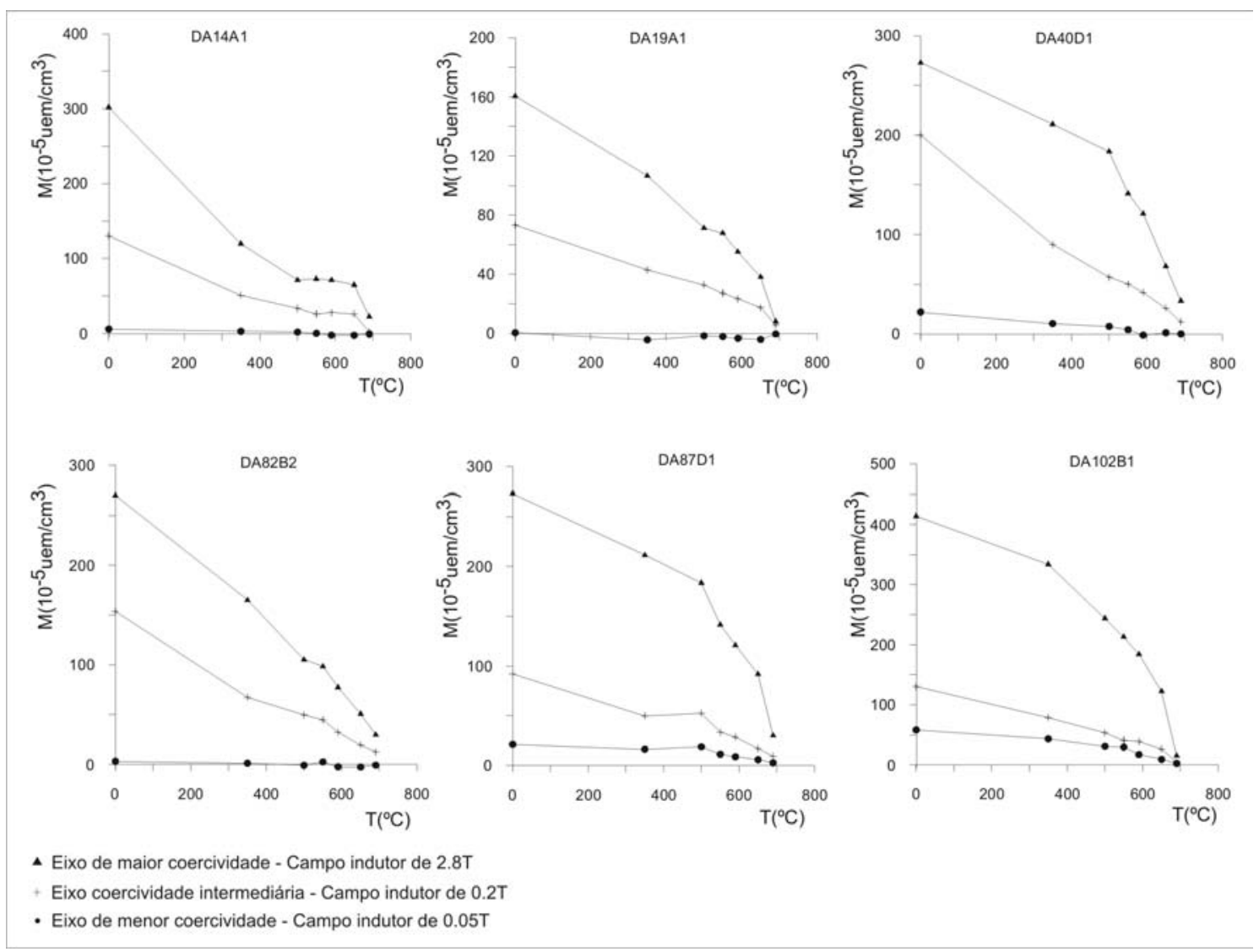

Figura 4.7. Curvas de desmagnetização após a magnetização em isotérmica.

Para todas as amostras a maior intensidade de magnetização se mostrou no eixo mais coercivo, exibindo uma alta concentração de grãos com alta coercividade e, apenas em alguns espécimes (DA-40, 87 e 102), o eixo de mínima coercividade possuía magnetização significativa. Na desmagnetização destes houve uma queda da intensidade na temperatura de $590^{\circ} \mathrm{C}$, indicando a presença do mineral magnetita. Para os espécimes DA-14 e 82 observa-se uma queda significativa na temperatura de $350^{\circ} \mathrm{C}$, podendo ser 
devido a presença de um mineral como a maghemita, que se transforma em hematita a $250^{\circ} \mathrm{C}$. Para algumas amostras (DA40 e 87) o eixo de maior coercividade sofreu uma queda da intensidade significativa também entre 550 e $690^{\circ} \mathrm{C}$. Indicando a presença de um mineral de composição distinta da hematita, porém com coercidade alta. Portanto este teste confirma a presença do mineral magnetita e mostra uma grande diversidade de composição e tamanho de grãos.

\subsubsection{Observação de lâminas delgadas}

Foram observadas lâminas delgadas utilizando um microscópio ótico. Foi observado que o pigmento vermelho (hematita) envolve os grãos de quartzo, como afirmado por Campos \& Dardenne (1994) e também aparece como cimento da rocha, cimento ferruginoso. A Figura 4.8 mostra algumas fotos tiradas no microscópio utilizando aumento de 40 ou 60 vezes e nicóis cruzados ou paralelos.

Na Figura 4.8A vemos um grão bem arredondado, envolto por grãos menores e cimento vermelho (ferruginoso). Em B um grão policristalino, envolto pelo cimento ferruginoso que penetra em suas fissuras. Em C e D cimento ferruginoso entre os grãos de quartzo. Em E o pigmento como uma película envolvendo o grão de quartzo e em $\mathrm{F}$ dois grãos de quartzo separados pelo cimento ferruginoso.

Em todas as lâminas foi observada uma coloração vermelha, dada por hematita, envolvendo os grãos de quartzo como uma película e como cimento. De acordo com Campos \& Dardenne (1994) esta película mostra o caráter eogenético da deposição do óxido de ferro (hematita). Em todas as amostras os grãos de quartzo estão isolados no cimento, sem contato, como vemos na Figura $4.8 \mathrm{~F}$, isso indica que não houve muita compactação, assim como afirmam Campos \& Dardenne (1994).

Apesar da indicação da presença de magnetita obtida nos dados magnéticos, não se observou a presença desses opacos na lâminas delgadas, talvez pela pouca quantidade em que deve existir, como também indicam os testes magnéticos. 


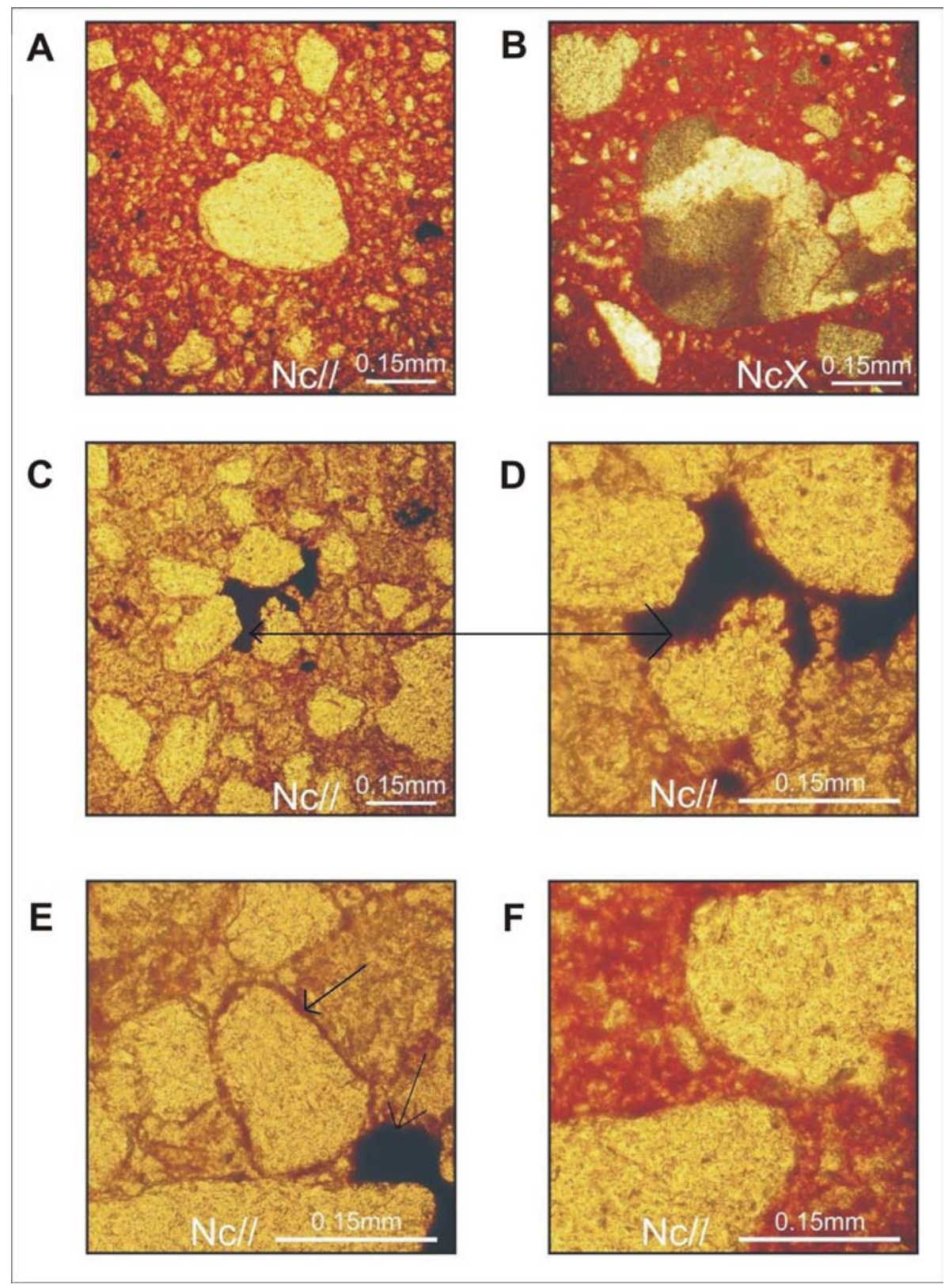

Figura 4.8. Exemplos de fotos tiradas em microscópio ótico de lâminas delgadas. Onde NcX significa nicóis cruzados e Nc//, nicóis paralelos. 


\section{RESULTADOS}

As direções de magnetização características identificadas através da análise de componentes principais (Cap. 4) resultaram em direções médias para cada sítio dandose peso um por espécime. Esses resultados estão dispostos na Tabela 5.1. Como o número de amostras por sítio é baixo (de 3 a 4) os valores do parâmetro $\alpha_{95}$, círculo de confiança de Fisher (1953) são relativamente altos, apesar da estabilidade (alta coercividade) das amostras. Isto pode ser explicado, em parte, pelo fato de que diferentes espécimes de um mesmo sítio (nível estratigráfico) não significam exatamente o mesmo "instante" no tempo geológico e podem ter registrado variações do campo geomagnético. Por outro lado, perturbações do ambiente de deposição, podem também levar a alguma modificação do registro magnético, aumentando a dispersão e diminuindo a confiabilidade do resultado.

O histograma da Figura 5.1 revela que a grande maioria dos sítios apresenta $\alpha_{95}$ de até $18^{\circ}$, concentrando-se entre 12 e $16^{\circ}$. Decidiu-se, então estabelecer um nível de corte para $\alpha_{95}>18^{\circ}$, considerando-se que dispersão maior que esse limite poderia indicar imprecisões do registro magnético. Entretanto, nota-se na Tabela 5.1, que a direção média geral considerando-se todos os dados das duas formações e a média geral considerando-se somente os dados que atendem ao nível de corte, não é afetada significativamente e que os parâmetros estatísticos também não se modificam.

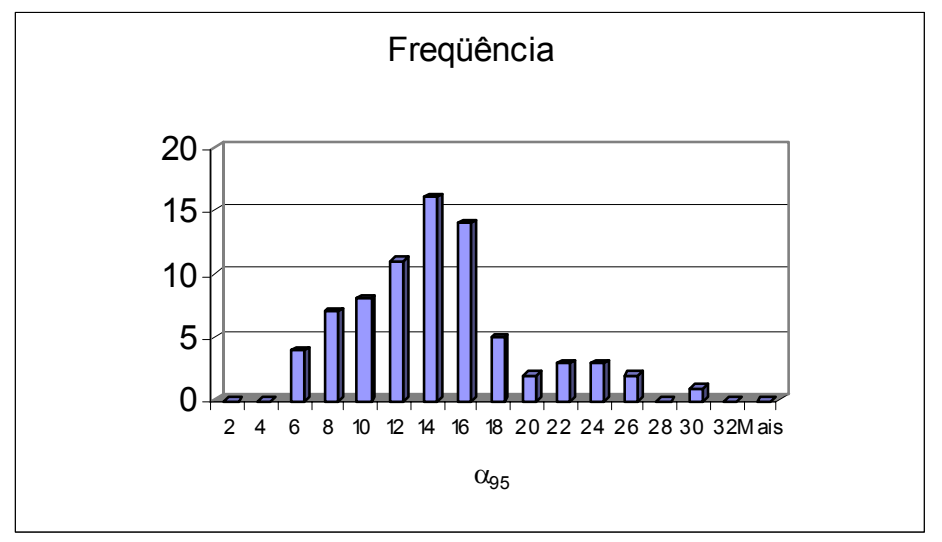

Figura 5.1. Histograma de valores de $\alpha_{95}$ para as direções médias dos sítios. 
As direções de magnetização características de cada sítio de amostragem estão representadas em projeção estereográfica (Figura 5.2). Todas as direções são de polaridade reversa, porém alguns sítios mostram direções anômalas que podem estar relacionadas a excursões geomagnéticas ou devem-se a perturbações do registro magnético. Entretanto, deve-se notar a coerência dessas direções, favorecendo a hipótese de registro real de variações geomagnéticas.

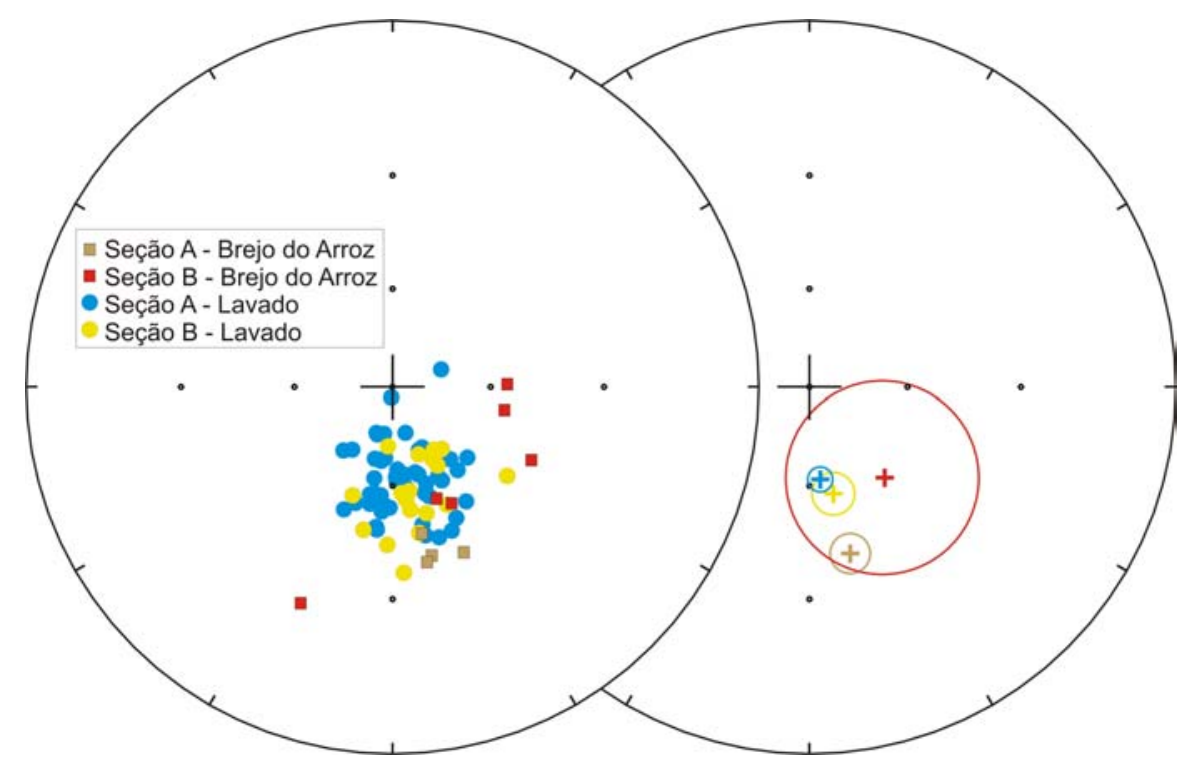

Figura 5.2. Projeção estereográfica das distribuições das diferentes seções.

A distribuição dos dados das seções do Membro Brejo do Arroz difere um pouco das encontradas para as outras seções; a seção A apresenta inclinações menores e a seção $\mathrm{B}$ apresenta maior número de dados anômalos As direções médias correspondentes não coincidem com aquelas calculadas para as seções do Membro Lavado. Entretanto, o número de sítios de amostragem para as duas seções do Membro Brejo do Arroz (A e B) é muito menor e a dispersão dos dados da seção B é maior, como visto pelo grande círculo de confiança. No caso da seção A a tendência para inclinações menores possa refletir diferença de idades, esta hipótese só poderá ser investigada com uma amostragem maior. As médias das seções A e B do Lavado são compatíveis entre si, havendo superposição parcial dos círculos de confiança. 
Tabela 5.1. Médias das direções por sítio, parâmetros estatísticos e pólos geomagnéticos virtuais.

\begin{tabular}{|c|c|c|c|c|c|c|c|c|c|c|}
\hline \multirow[t]{2}{*}{ Sítio } & \multirow{2}{*}{$\begin{array}{c}\text { Altura Rel. } \\
\text { (m) }\end{array}$} & \multicolumn{5}{|c|}{ Direção de Magnetização Média } & \multicolumn{4}{|c|}{ Pólos Geomag. Virtuais } \\
\hline & & $\operatorname{Dec}\left({ }^{\circ}\right)$ & $\operatorname{lnc}\left({ }^{\circ}\right)$ & $\alpha_{95}\left(^{\circ}\right)$ & $\mathbf{N}$ & $\mathbf{k}$ & $\begin{array}{c}\text { Plong } \\
\text { ('E) }\end{array}$ & $\begin{array}{l}\text { Plat } \\
\left({ }^{\circ} \mathrm{S}\right)\end{array}$ & $\begin{array}{c}d p \\
\left(\alpha_{95}\right)\end{array}$ & $\begin{array}{l}\mathrm{dm} \\
(\mathrm{k})\end{array}$ \\
\hline \multicolumn{11}{|c|}{ Membro Brejo do Arroz - Seção A } \\
\hline 11 & 0 & 168.9 & 38.2 & 13.9 & 3 & 80 & 21.0 & 78.8 & 9.7 & 16.5 \\
\hline 12 & 0.23 & 156.6 & 37.8 & 7.0 & 3 & 312 & 30.6 & 67.6 & 4.9 & 8.3 \\
\hline 13 & 0.28 & 166.9 & 39.6 & 14.8 & 3 & 70 & 19.6 & 76.7 & 10.6 & 17.7 \\
\hline 14 & 0.48 & 168.6 & 45.7 & 12.4 & 3 & 100 & 359.4 & 75.6 & 10.1 & 15.8 \\
\hline 15 & 0.53 & 170.3 & 38.1 & 14.7 & 3 & 72 & 18.9 & 80.0 & 10.3 & 17.4 \\
\hline \multicolumn{11}{|c|}{ Membro Brejo do Arroz - Seção B } \\
\hline 18 & 5.0 & 152.7 & 51.0 & 10.0 & 4 & 85 & 8.3 & 61.1 & 9.1 & 13.5 \\
\hline $23^{2,3}$ & 5.4 & 117.6 & 43.7 & 11.5 & 3 & 116 & 24.4 & 31.6 & 9.0 & 14.4 \\
\hline $27^{1}$ & 5.5 & 158.3 & 53.9 & 21.5 & 4 & 19 & 358.0 & 63.7 & 21.1 & 30.1 \\
\hline $31^{2,3}$ & 5.9 & 88.7 & 55.2 & 13.2 & 3 & 87 & 9.7 & 8.6 & 13.4 & 18.8 \\
\hline 34 & 8.4 & 101.4 & 55.4 & 8.4 & 3 & 214 & 11.4 & 18.8 & 8.5 & 12.0 \\
\hline $38^{1,2,3}$ & 0.0 & 203.1 & 24.8 & 23.6 & 3 & 28 & 218.3 & 67.4 & 13.6 & 25.3 \\
\hline \multicolumn{11}{|c|}{ Membro Lavado Seção A-(A1) } \\
\hline 40 & 6.82 & 194.0 & 67.4 & 17.9 & 3 & 48 & 299.0 & 54.7 & 24.8 & 29.8 \\
\hline 41 & 6.97 & 191.4 & 61.7 & 7.0 & 3 & 310 & 296.5 & 62.1 & 8.4 & 10.8 \\
\hline 42 & 7.07 & 191.0 & 54.2 & 11.1 & 3 & 124 & 288.0 & 69.5 & 11.0 & 15.6 \\
\hline 43 & 7.22 & 172.2 & 59.2 & 11.5 & 3 & 117 & 329.2 & 65.8 & 12.9 & 17.2 \\
\hline 44 & 7.37 & 176.7 & 64.8 & 8.7 & 3 & 199 & 319.1 & 59.9 & 11.3 & 14.0 \\
\hline 45 & 7.47 & 173.6 & 58.9 & 4.6 & 3 & 705 & 326.9 & 66.4 & 5.1 & 6.9 \\
\hline 46 & 7.67 & 163.5 & 62.2 & 8.8 & 3 & 196 & 338.8 & 59.8 & 10.7 & 13.7 \\
\hline 47 & 7.82 & 167.4 & 45.1 & 13.0 & 3 & 91 & 2.1 & 74.7 & 10.4 & 16.5 \\
\hline 48 & 8.02 & 147.1 & 49.4 & 12.4 & 3 & 100 & 14.3 & 57.1 & 10.9 & 16.5 \\
\hline 49 & 8.12 & 157.5 & 44.2 & 7.7 & 3 & 258 & 17.0 & 67.2 & 6.1 & 9.7 \\
\hline 50 & 8.12 & 185.0 & 52.5 & 15.0 & 4 & 38 & 300.1 & 73.0 & 14.2 & 20.6 \\
\hline 51 & 8.32 & 161.4 & 55.3 & 14.8 & 3 & 70 & 351.9 & 64.8 & 15.0 & 21.1 \\
\hline 52 & 8.37 & 192.0 & 56.9 & 7.7 & 4 & 255 & 289.9 & 66.7 & 8.1 & 11.2 \\
\hline 53 & 8.57 & 186.0 & 68.1 & 16.9 & 4 & 30 & 308.0 & 55.2 & 23.8 & 28.4 \\
\hline $54^{2,3}$ & 9.37 & 187.5 & 86.8 & 17.3 & 4 & 29 & 313.7 & 23.1 & 34.3 & 34.4 \\
\hline 55 & 9.62 & 201.8 & 50.6 & 11.6 & 3 & 114 & 264.9 & 65.4 & 10.5 & 15.6 \\
\hline \multicolumn{11}{|c|}{ Membro Lavado Seção A-(A2) } \\
\hline 56 & 1.95 & 165.1 & 63.1 & 13.8 & 3 & 81 & 335.7 & 59.5 & 17.1 & 21.7 \\
\hline 57 & 2.95 & 198.0 & 74.7 & 12.8 & 3 & 53 & 302.7 & 43.6 & 21.2 & 23.3 \\
\hline $58^{1}$ & 3.15 & 162.7 & 43.7 & 22.9 & 4 & 17 & 13.0 & 71.7 & 17.8 & 28.6 \\
\hline $59^{1}$ & 3.45 & 152.9 & 59.5 & 22.0 & 4 & 18 & 353.9 & 56.8 & 24.8 & 33.0 \\
\hline 60 & 3.65 & 167.7 & 48.1 & 13.0 & 3 & 90 & 354.8 & 73.2 & 11.1 & 17.0 \\
\hline 61 & 3.9 & 186.8 & 48.1 & 13.9 & 3 & 80 & 289.0 & 76.1 & 11.9 & 18.2 \\
\hline 62 & 3.9 & 186.3 & 57.1 & 13.5 & 3 & 84 & 301.0 & 68.3 & 14.3 & 19.7 \\
\hline 63 & 4.1 & 172.0 & 63.0 & 10.3 & 4 & 80 & 326.6 & 61.5 & 12.7 & 16.2 \\
\hline \multicolumn{11}{|c|}{ Membro Lavado Seção A-(A3) } \\
\hline 64 & 0 & 153.8 & 69.4 & 9.6 & 3 & 166 & 338.1 & 48.3 & 14.0 & 16.4 \\
\hline $65^{2,3}$ & 0.3 & 70.2 & 74.0 & 8.5 & 3 & 210 & 342.6 & 5.1 & 13.8 & 15.3 \\
\hline 66 & 0.5 & 141.1 & 61.8 & 13.7 & 3 & 82 & 357.8 & 47.9 & 16.4 & 21.2 \\
\hline 67 & 0.7 & 177.6 & 61.2 & 9.6 & 3 & 167 & 318.7 & 64.4 & 11.3 & 14.7 \\
\hline 68 & 0.85 & 177.8 & 62.6 & 12.9 & 3 & 92 & 318.0 & 62.7 & 15.8 & 20.2 \\
\hline 69 & 0.95 & 141.7 & 58.0 & 13.4 & 3 & 86 & 3.5 & 50.1 & 14.5 & 19.7 \\
\hline 70 & 1.05 & 160.7 & 59.0 & 10.1 & 3 & 150 & 346.8 & 61.5 & 11.2 & 15.1 \\
\hline 71 & 1.2 & 164.1 & 75.4 & 14.1 & 4 & 43 & 324.5 & 42.9 & 23.7 & 25.8 \\
\hline 72 & 1.35 & 181.4 & 53.7 & 12.5 & 3 & 98 & 310.7 & 72.5 & 12.2 & 17.5 \\
\hline $73^{1}$ & 1.55 & 186.3 & 47.4 & 21.6 & 3 & 33 & 289.5 & 76.9 & 18.2 & 28.0 \\
\hline $74^{2}$ & 1.95 & 213 & 67.2 & 15.1 & 3 & 38 & 283.3 & 47.5 & 20.8 & 25.1 \\
\hline 75 & 2.55 & 184.9 & 54.8 & 10.2 & 3 & 148 & 302.3 & 70.9 & 10.2 & 14.4 \\
\hline $76^{1}$ & 2.75 & 197.8 & 53.4 & 18.5 & 3 & 45 & 275 & 66.5 & 17.9 & 25.7 \\
\hline 77 & 3.75 & 157.2 & 69.1 & 17.3 & 3 & 52 & 336 & 49.9 & 25.0 & 29.4 \\
\hline 78 & 4.75 & 162.9 & 56.5 & 11.9 & 4 & 61 & 347.8 & 64.7 & 12.4 & 17.2 \\
\hline
\end{tabular}


Continuação da Tabela 5.1.

\begin{tabular}{|c|c|c|c|c|c|c|c|c|c|c|}
\hline \multirow[t]{2}{*}{ Sítio } & \multirow{2}{*}{$\begin{array}{c}\text { Altura Rel. } \\
\text { (m) }\end{array}$} & \multicolumn{5}{|c|}{ Direção de Magnetização Média } & \multicolumn{4}{|c|}{ Pólos Geomag. Virtuais } \\
\hline & & $\operatorname{Dec}\left({ }^{\circ}\right)$ & $\operatorname{lnc}\left({ }^{\circ}\right)$ & $\alpha_{95}\left(^{\circ}\right)$ & $\mathbf{N}$ & k & $\begin{array}{l}\text { Plong } \\
\left({ }^{\circ} \mathrm{E}\right)\end{array}$ & $\begin{array}{l}\text { Plat } \\
\text { ('S) }\end{array}$ & $\begin{array}{c}d p \\
\left(\alpha_{95}\right)\end{array}$ & $\begin{array}{l}\mathrm{dm} \\
\text { (k) }\end{array}$ \\
\hline \multicolumn{11}{|c|}{ Membro Lavado Seção A-(A3) } \\
\hline 79 & 4.75 & 153.9 & 46.8 & 14.9 & 3 & 69 & 14.8 & 63.4 & 12.4 & 19.2 \\
\hline 80 & 5 & 133.1 & 58.8 & 11.1 & 3 & 124 & 5.4 & 43.5 & 12.3 & 16.5 \\
\hline 81 & 5.25 & 188.8 & 67.1 & 7.7 & 3 & 256 & 304.3 & 56.2 & 10.6 & 12.8 \\
\hline 82 & 5.52 & 152 & 58 & 14.9 & 3 & 69 & 357.1 & 57.2 & 16.2 & 22.0 \\
\hline $83^{2}$ & 5.72 & 218.1 & 65.4 & 5.2 & 4 & 554 & 277.6 & 46.2 & 6.8 & 8.4 \\
\hline 84 & 6.12 & 189.8 & 57.4 & 14.7 & 3 & 71 & 294.4 & 67.1 & 15.7 & 21.5 \\
\hline 85 & 6.52 & 190.4 & 75.4 & 11.7 & 4 & 63 & 307.9 & 43.7 & 19.7 & 21.4 \\
\hline 86 & 6.82 & 199.6 & 75.1 & 13.8 & 4 & 46 & 302.2 & 42.7 & 23.0 & 25.2 \\
\hline \multicolumn{11}{|c|}{ Membro Lavado Seção B } \\
\hline 87 & 10.35 & 181.9 & 43.5 & 7.6 & 3 & 265 & 302.1 & 81.8 & 5.9 & 9.5 \\
\hline 88 & 10.05 & 171.7 & 52.8 & 10.3 & 3 & 143 & 337.7 & 72.4 & 9.8 & 14.2 \\
\hline 89 & 8.75 & 141.3 & 65.8 & 8.9 & 3 & 191 & 351.3 & 46.1 & 11.8 & 14.5 \\
\hline $90^{1}$ & 8.5 & 158.6 & 67.9 & 28.1 & 4 & 12 & 336.4 & 52.4 & 39.4 & 47.1 \\
\hline 91 & 8.2 & 155.0 & 51.2 & 5.3 & 3 & 543 & 6.9 & 63.2 & 4.9 & 7.2 \\
\hline 92 & 7 & 174.9 & 57.7 & 14.6 & 4 & 41 & 325.3 & 68.6 & 15.7 & 21.4 \\
\hline $93^{1}$ & 6.8 & 176.5 & 36.3 & 24.4 & 3 & 27 & 4.0 & 85.7 & 16.6 & 28.4 \\
\hline $94^{1}$ & 6.6 & 191.6 & 46.8 & 26.0 & 4 & 13 & 271.1 & 74.9 & 21.6 & 33.5 \\
\hline $95^{2}$ & 6.35 & 127.6 & 46.9 & 14.7 & 3 & 71 & 21.8 & 40.9 & 12.2 & 19.0 \\
\hline 96 & 3.85 & 169.6 & 46.1 & 7.7 & 3 & 258 & 356.1 & 76.1 & 6.3 & 9.9 \\
\hline 97 & 3.45 & 173.2 & 55.8 & 14.7 & 3 & 71 & 330.6 & 70.1 & 15.1 & 21.1 \\
\hline 98 & 2.85 & 164.9 & 50.9 & 13.2 & 4 & 50 & 355.4 & 70.3 & 12.0 & 17.8 \\
\hline 99 & 2.85 & 170.8 & 58.1 & 5.6 & 3 & 480 & 333.0 & 67.2 & 6.1 & 8.3 \\
\hline 100 & 2.55 & 150.0 & 62.4 & 15.5 & 4 & 36 & 351.7 & 53.5 & 18.9 & 24.2 \\
\hline 101 & 1.05 & 150.8 & 64.9 & 17.4 & 4 & 29 & 347.0 & 52.0 & 22.6 & 28.0 \\
\hline $102^{1}$ & 0.55 & 184.4 & 71.7 & 18.7 & 4 & 25 & 310.4 & 50.8 & 28.9 & 32.9 \\
\hline $103^{1}$ & 0.25 & 200.3 & 55.2 & 22.1 & 4 & 18 & 273.7 & 64.3 & 22.4 & 31.4 \\
\hline 104 & 0 & 146.5 & 67.0 & 14.3 & 3 & 76 & 346.5 & 48.0 & 19.6 & 23.7 \\
\hline Média & Geral & 168.6 & 58.9 & 3.4 & 76 & 24 & 334.1 & 63.8 & 4.6 & 14 \\
\hline Média & $\left.\alpha_{95} \leq 18\right)$ & 166.0 & 59.9 & 3.6 & 65 & 25 & 336.3 & 62.1 & 4.9 & 14 \\
\hline Média & colat. $\leq 30^{\circ}$ ) & 169.3 & 58.0 & 3.0 & 57 & 40 & 334.1 & 65.3 & 3.8 & 25 \\
\hline Média & colat. $\leq 40^{\circ}$ ) & 169.5 & 58.5 & 3.1 & 60 & 36 & 332.8 & 64.9 & 4.1 & 21 \\
\hline Média & Membro Lavado & 170.4 & 60.3 & 3.1 & 54 & 40 & 330.0 & 63.5 & 4.5 & 22 \\
\hline
\end{tabular}

${ }^{1}$ sítios com $\alpha_{95}>18^{\circ} ;{ }^{2}$ sítios não contidos na calota de $30^{\circ} ;{ }^{3}$ sítios não contidos na calota de $40^{\circ} ;$ Altura Rel. - Altura relativa;

Dec-Declinação; Inc-Inclinação; Plong-Longitude; Plat-Latitude; dp e dm-semi-eixos da elipse de $95 \%$ de

confiabilidade; colat. - colatitude

\subsection{Testes da estabilidade da magnetização}

A estabilidade da magnetização remanente foi testada comparando-se a magnetização característica do Grupo Santa Fé com a magnetização do Grupo Bambuí que aflora no ponto 1 de amostragem (base da seção A do Membro Brejo do Arroz), conforme descrito anteriormente. Após desmagnetizações realizadas segundo os procedimentos descritos para as amostras do Grupo Santa Fé (Capítulo 4), obteve-se os resultados mostrados na Tabela 5.2. Nessa tabela estão contidos também os resultados para os três seixos pingados amostrados nas seções do Membro Brejo do Arroz. 
Tabela 5.2. Direções médias para os sítios do embasamento e dos seixos.

\begin{tabular}{|c|c|c|c|c|c|}
\hline \multirow[t]{2}{*}{ Sitio } & \multicolumn{5}{|c|}{ Direção de Magnetização Média } \\
\hline & $\operatorname{Dec}\left({ }^{\circ}\right)$ & $\operatorname{Inc}\left(^{\circ}\right)$ & $\begin{array}{l}\alpha_{95}\left(^{\circ}\right) \\
(\mathrm{mad})\end{array}$ & $\mathbf{N}$ & $\mathbf{k}$ \\
\hline \multicolumn{6}{|c|}{ Embasamento } \\
\hline $1^{*}$ & 193.9 & -42.6 & 26.7 & 3 & 22 \\
\hline 2 & 223.5 & -33.4 & 25.3 & 3 & 25 \\
\hline 3 & 248 & -31 & 42 & 2 & 37 \\
\hline 4 & 232.5 & -28.6 & 40.9 & 2 & 39 \\
\hline 5 & 255.1 & -0.5 & 28.8 & 2 & 77 \\
\hline 6 & 252.6 & 1.5 & 18.7 & 3 & 45 \\
\hline 7 & 237.4 & 6.9 & 17.8 & 2 & 198 \\
\hline 8 & 244.7 & -0.5 & 34 & 2 & 56 \\
\hline 9 & 240.4 & -1.4 & 15.8 & 2 & 252 \\
\hline $10^{*}$ & 13.4 & -44.5 & 25.3 & 2 & 100 \\
\hline média & 242.2 & -10.9 & 13.8 & 8 & 17 \\
\hline \multicolumn{6}{|c|}{ Seixos } \\
\hline 16 & 168.7 & -34.2 & (14.4) & & \\
\hline 17 & 244.4 & 34 & (1.9) & & \\
\hline 37 & 329.5 & -43.4 & 19.7 & 2 & 163 \\
\hline tirad & & & & & \\
\hline
\end{tabular}

As direções encontradas tanto para o embasamento local quanto para os seixos são distintas daquelas do Grupo Santa Fé (Figura 5.6), portanto pode-se dizer que não ocorreu nenhum evento de remagnetização intenso o suficiente que afetasse $o$ embasamento, os seixos e os sedimentos do Grupo Santa Fé.

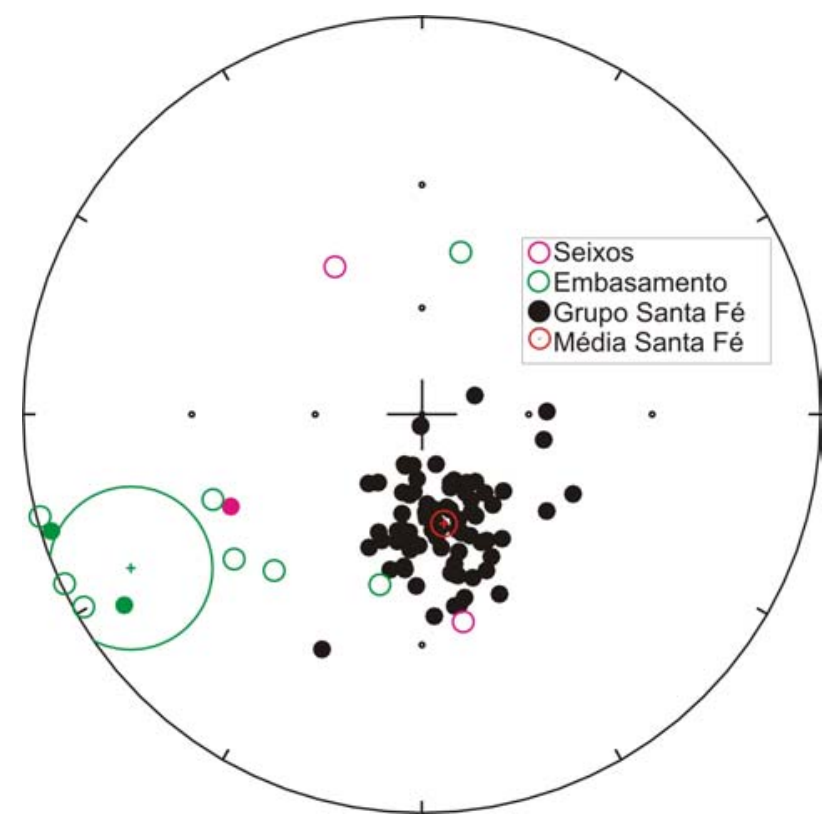

Figura 5.6. Comparação entre as direções do Grupo Santa Fé, embasamento local (Grupo Bambuí) e os seixos caídos. 


\subsection{Magnetoestratigrafia}

Utilizando-se os dados de direções médias por sítio foram construídas colunas magnetoestratigráficas para todas as seções (Figura 5.2). Estas seções magnetoestratigráficas correspondem às variações da declinação e inclinação da magnetização em função da altura relativa do sítio. As barras de erro utilizadas são dadas pela metade de $\alpha_{95}$. Este tipo de projeção permite a observação da variação da direção de magnetização registrada através do tempo.

No arenito da seção A do Brejo do Arroz, por se tratar de uma seção de espessura de apenas 60 centímetros, espera-se um registro magnético com pouca ou nenhuma variação por ser referente a um pequeno intervalo de tempo, contanto que a magnetização corresponda exatamente ao registro do campo geomagnético, e que não existam tendências em direções dadas pelas condições de sedimentação. Nos folhelhos da seção B do Brejo do Arroz foram encontradas variações de grande amplitude na declinação da magnetização ao longo dos sítios de amostragem e uma tendência a direções anômalas ou intermediárias na parte superior da seção (últimos 3m, aproximadamente). Em termos de tempo esse intervalo pode ser bastante longo e a amostragem é muito esparsa para se concluir sobre o significado desse comportamento.

As subseções A1, A2 e A3 do Membro Lavado, localizadas no mesmo ponto de amostragem são complementares. A1 e A3 formam um contínuo, com boa coerência dos dados magnéticos. A correspondência entre as subseções A2 e A3, paralelas e distantes cerca de 50m, é aproximada, uma vez que a amostragem foi feita dentro de ravinas e a correta visualização dos níveis não era possível. Ao todo a seção A compreende $10 \mathrm{~m}$ de espessura e as variações da magnetização aí registradas são bastante coerentes com ciclos de variação secular. Apenas na base de A3 nota-se variação de maior amplitude em declinação, resultando em direção anômala ou transicional. A seção B do Membro Lavado, a aproximadamente $100 \mathrm{~km}$ da seção A, e também compreendendo cerca de $10 \mathrm{~m}$ de espessura, apresenta essencialmente o mesmo comportamento magnético da seção A, com variações geomagnéticas de mesma amplitude. 


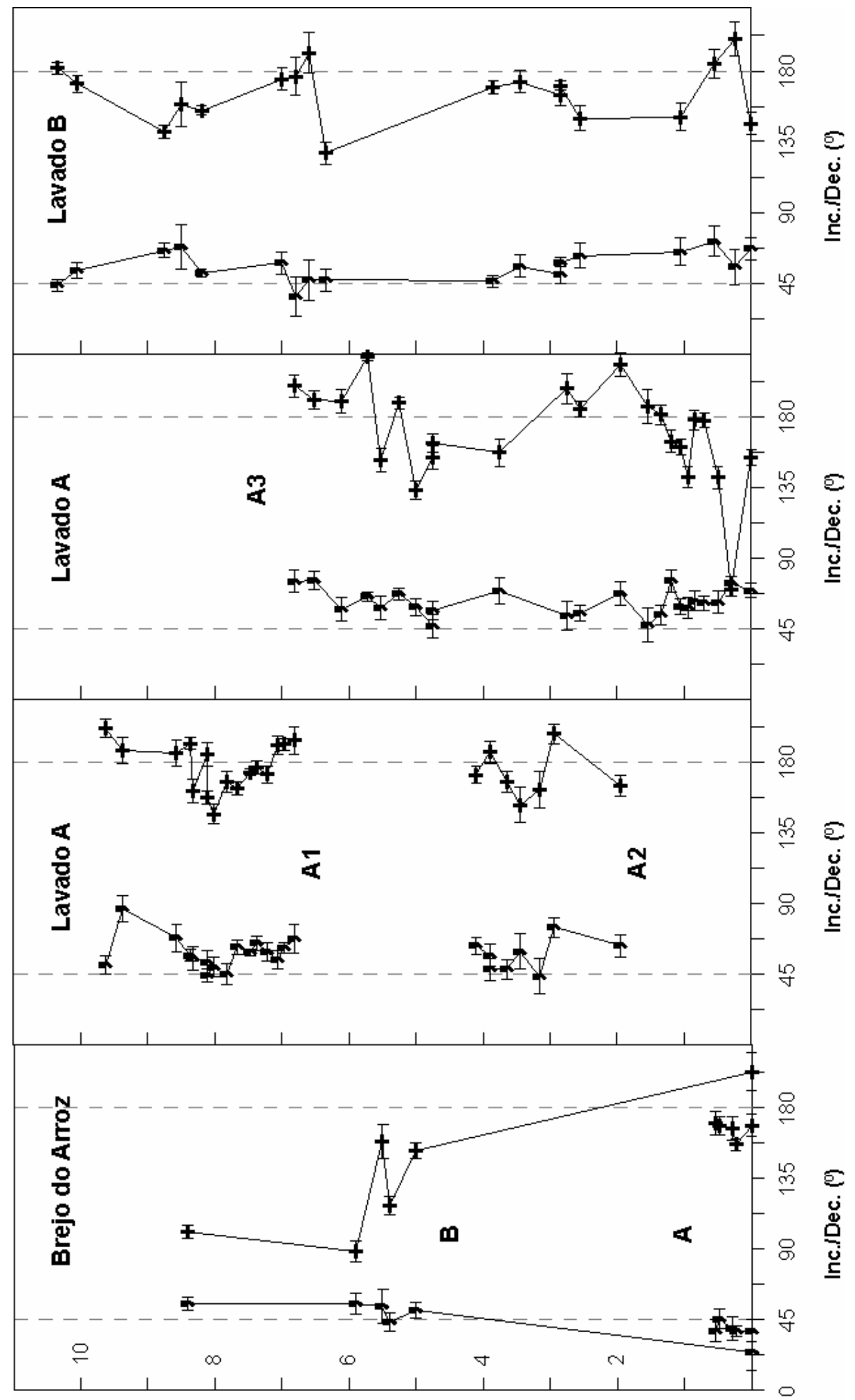

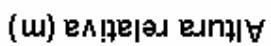

Figura 5.3. Variação da declinação e inclinação da magnetização em função da altura relativa dos sítios estudados para as seções A e B do Membro Brejo do Arroz e das seções A (subseções $\mathrm{A} 1, \mathrm{~A} 2, \mathrm{~A} 3)$ e $\mathrm{B}$ do Membro Lavado. Os quadrados correspondem à inclinação e as cruzes, à declinação. As barras de erro equivalem a meio $\alpha_{95}$ das médias dos sítios. 
Vale notar que as inclinações magnéticas registradas para as seções A e B do Membro Lavado, situam-se sempre acima de $45^{\circ}$ (a exceção de um sítio da seção B), ao passo que, para o Membro Brejo do Arroz. A base da seção B, bem como a Seção A, apresentam inclinações menores que $45^{\circ}$. Isto pode ser um indicativo de que pode existir diferença real de idade entre os dois membros.

Para se investigar possíveis influências da sedimentação no registro magnético, procurou-se verificar a correlação entre a declinação magnética e a anisotropia de suscetibilidade magnética, através da declinação e inclinação do eixo de maior susceptibilidade magnética $\left(\mathrm{K}_{1}\right)$ dos sítios que apresentaram lineação (Figura 5.3).

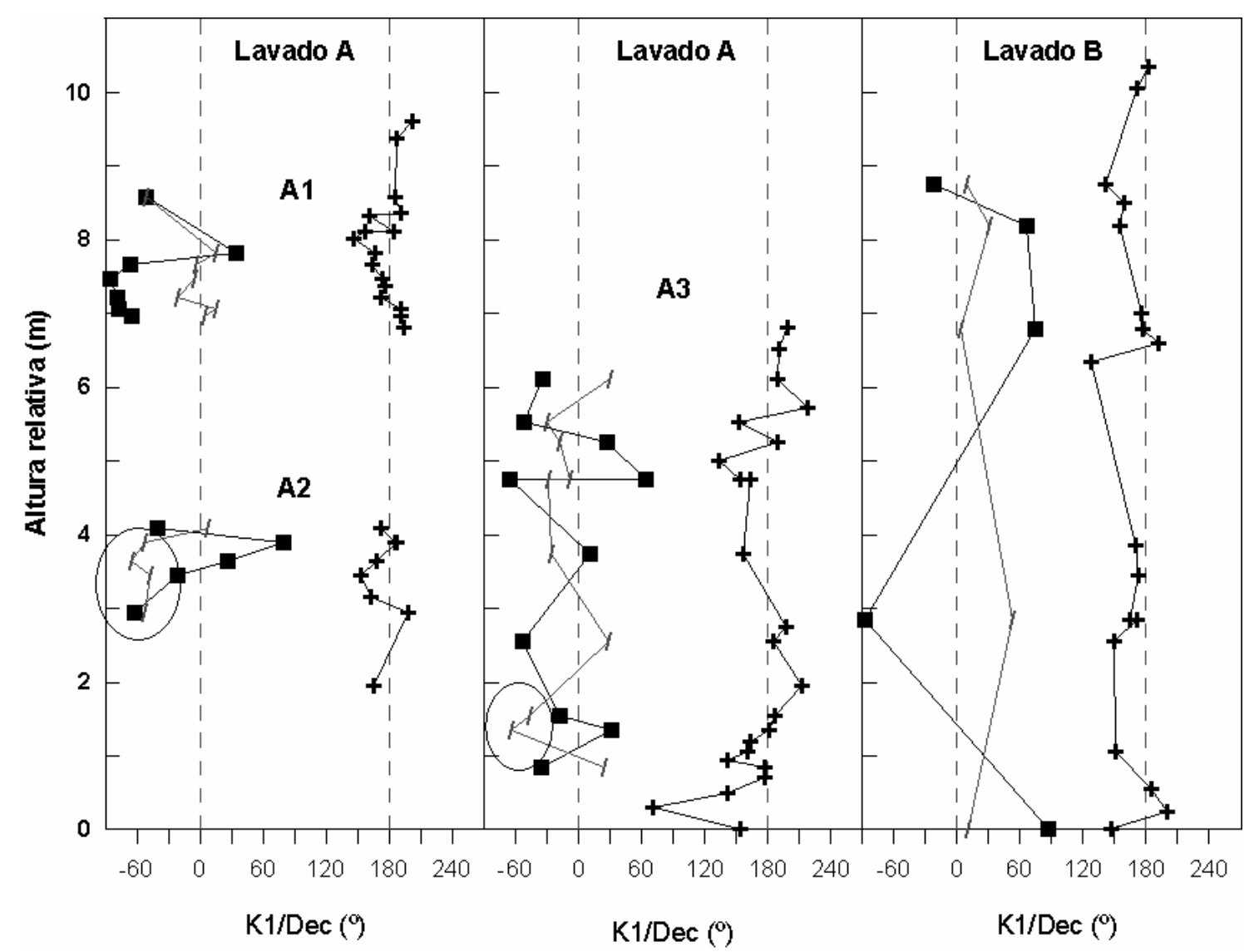

Figura 5.3. Variação da declinação de magnetização (cruzes) e a declinação (quadrados) e inclinação (barras inclinadas) de K1 ao longo da estratigrafia para as seções do Membro Lavado.

Para a seção B do Membro Lavado, os sítios que apresentaram lineação são em pequeno número para que se avalie qualquer correlação. Já para a seção A, são muito 
mais freqüentes os sítios com lineação e em alguns setores das curvas de variação podese sugerir estreita correlação entre variação magnética e variação de ASM (por exemplo, a subseção A2). Entretanto, os sítios que apresentam variações mais abruptas de declinação, e que poderiam refletir condições da sedimentação, não necessariamente demonstram correspondência direta com a variação do eixo K1, ou sequer apresentaram lineação.

Um aspecto importante dessas curvas de variação, entretanto, é a possibilidade de refinar a correspondência entre as subseções A2 e A3. Na Figura 5.3 foram destacados (pontos circundados) os níveis em que a inclinação de $\mathrm{K}_{1}$ é próxima de $60^{\circ}$. Este comportamento é característico nestes níveis, não sendo verificado em outros níveis ao longo da seção, por isso pode-se dizer que os pontos destacados em A2 correspondem a alturas aproximadamente iguais aos pontos destacados em A3. Essas inclinações elevadas do eixo $\mathrm{K} 1$, ou seja, fortes desvios do plano horizontal, não se refletem na magnetização. Entretanto, servem como prováveis marcadores para a correlação lateral das seções.

\subsection{Pólos Geomagnéticos Virtuais}

Para cada sítio do Grupo Santa Fé foi calculado um pólo geomagnético virtual (PGV) e o pólo paleomagnético Santa Fé foi calculado dando-se peso um aos PGVs individuais. A Figura 5.5A mostra a distribuição dos PGVs e a média destes. Ao calcular um pólo paleomagnético deve-se considerar os PGVs que representem o registro da variação secular. A distribuição esperada para os PGVs nessas condições é aquela que fica confinada em um círculo de raio de $30^{\circ}$ a $40^{\circ}$; os que estão além dessa distribuição devem estar relacionados a excursões ou mesmo inversões geomagnéticas e não devem ser considerados na média final. Para melhor se avaliar a dispersão e distribuição dos PGVs encontrados neste trabalho, rotacionou-se o pólo médio de forma a coincidir com o pólo sul geográfico (Figura 5.5 B). Poucos são os pontos que se colocam além do círculo de $30^{\circ}$ e, portanto, não há diferença significativa, tanto em coordenadas como em parâmetros estatísticos, entre as médias dos PGVs calculadas com dados situados até $30^{\circ}$ ou $40^{\circ}$ do pólo geográfico, como ser observado na Tabela 5.1. Adotou-se, então o limite de $40^{\circ}$ para que fosse incluído o maior número possível 
de dados, aumentando a probabilidade de se eliminar adequadamente os efeitos variação secular.
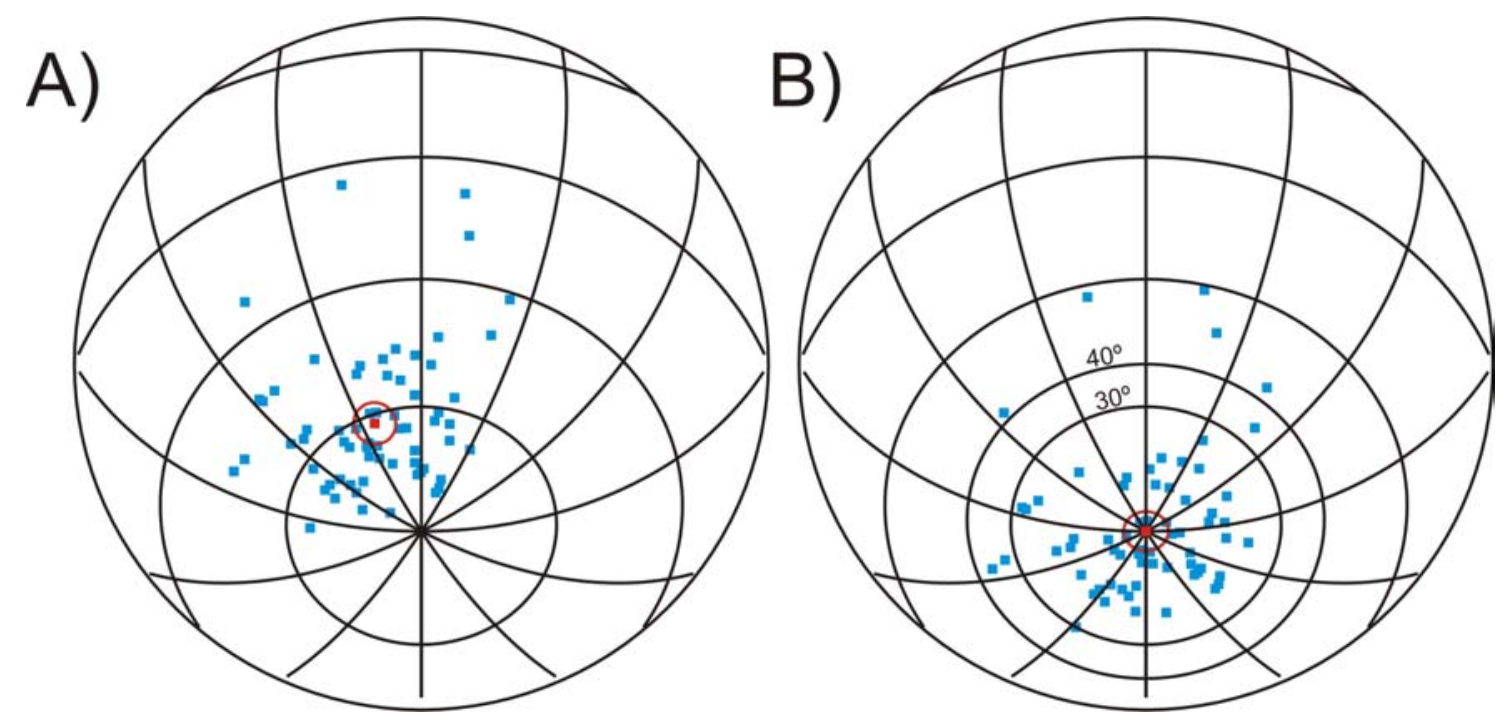

Figura 5.5. A) Distribuição dos PGVs com a respectiva média e círculo de confiança de $95 \%$; B) rotação dos PGVs com a média coincidente com o pólo Sul, destacando-se os círculos-limite de $30^{\circ}$ e $40^{\circ}$.

Os dados situados além do círculo de co-latitudes de $40^{\circ}$ foram então rejeitados e o novo pólo paleomagnético calculado situa-se a $332.8^{\circ} \mathrm{E} 64.9^{\circ} \mathrm{S}\left(\mathrm{N}=60 ; \alpha_{95}=4.1^{\circ}\right.$; $\mathrm{k}=21$ ). Este pólo é representativo do Grupo Santa Fé e não se levou em consideração possíveis diferenças de idade entre os membros Lavado e Brejo do Arroz, já que o número limitado de sítios deste último não permite calcular um pólo paleomagnético de confiança. 


\section{DISCUSSÕES E CONCLUSÕES}

Neste capítulo será discutida a qualidade do pólo paleomagnético obtido neste trabalho e como este se insere num contexto global.

\subsection{Confiabilidade do Pólo Paleomagnético Santa Fé}

Do ponto de vista da confiabilidade, o pólo paleomagnético para o Grupo Santa Fé (SF) satisfaz a pelo menos 5 dos 7 critérios estabelecidos por Van der Voo (1990):

1) número de amostras $(\mathrm{N}>24), \mathrm{k} \geq 10$ e $\alpha_{95} \leq 16$ : os parâmetros obtidos foram $\mathrm{N}=60$, $\alpha_{95}=4.1^{\circ}$ e $\mathrm{k}=21$;

2) desmagnetização detalhada: as amostras foram submetidas a dois processos de desmagnetização e as componentes características foram determinadas por análise de componentes principais (mínimo de 5 pontos e dispersão angular máxima $\leq 14^{\circ}$ );

3) controle estrutural e coerência tectônica com o bloco cratônico envolvido: a região estudada é uma região estável, não há possibilidade de rotações desconhecidas durante o intervalo de tempo abrangido pelo Grupo Santa Fé;

4) o pólo paleomagnético não se assemelha a paleopólos de idade mais jovem: o pólo paleomagnético SF está baseado exclusivamente em direções de polaridade reversa.

5) testes de campo que confinem a idade da magnetização: foram apresentadas evidências de que a magnetização é primária e de mesma idade da rocha, bem como testes de remagnetização comparando com rochas do embasamento e seixos pingados.

Os critérios não satisfeitos seriam:

6) idade bem determinada da rocha e a pressuposição de que a magnetização é da mesma idade da rocha: embora não existam determinações absolutas de idade, o intervalo de idade fica bem definido e relativamente restrito, por se inserir no Superchron Reverso do Permo-Carbonífero (SRPC); a idade do Grupo Santa Fé será discutida na seção 6.4 e a magnetização tem a idade da rocha, como demonstrado anteriormente; 
7) presença de reversões: neste trabalho não foi possível encontrar reversões porque as rochas se inserem no SRPC.

A idade da rocha não é exatamente bem determinada, se não forem consideradas as informações paleomagnéticas. Entretanto, Campos \& Dardenne (1994) atribuem uma datação aproximada no intervalo Permo-Carbonífero e atribuem a origem do pigmento vermelho (hematita) das rochas a películas de óxido de ferro que cobriram os grãos detríticos no início da diagênese. A presença de hematita, quando a origem data dos primórdios da diagênese, é uma garantia de que a magnetização primária deve ter sido preservada, uma vez que sua grande estabilidade magnética não permite remagnetizações por indução magnética. Além do mais, existem dois tipos de portadores magnéticos nessas rochas: magnetita e hematita, ambos tendo registrado a mesma direção de magnetização.

A ausência de inversões de polaridade, ao invés de ser um problema ou deficiência no tocante à qualidade dos resultados, é um fator que auxilia para se restringir à idade do Grupo, uma vez que foram encontradas inversões de polaridade na base e topo do SRPC, como será discutido mais adiante, limitando ainda mais a idade das rochas aqui estudadas.

\subsection{Qualidade dos Pólos Paleomagnéticos da América do Sul}

Os pólos paleomagnéticos para a América do Sul de idade aproximada à do Grupo Santa Fé foram encontrados na base de dados paleomagnéticos global da IAGA (International Association of Geomagnetism and Aeronomy). Selecionou-se apenas pólos com idades entre 240 e 300 Ma e com indicações de magnetização primária obtida através de desmagnetizações e análise das componentes principais. Esses pólos estão representados na Figura 6.1 e listados na Tabela 6.1.

O pólo do Grupo Mitu (Gilder et al., 2003) do Norte do Peru, Cordilheira dos Andes, foi obtido com seis sítios de red beds, que cobrem o Grupo Copacabana (Permiano Inferior) e é recoberto erosivamente pelo Grupo Pucará (Triássico Superior), portanto, de idade Permiano Superior a Triássico Inferior. O teste da dobra indicou uma remanência de idade pré-dobramento. O teste de reversões foi positivo, portanto o Grupo Mitu pode ter idade ligeiramente diferente do Grupo Santa Fé. 
Tabela 6.1. Pólos paleomagnéticos encontrados com idades entre 240 e 300 Ma para a placa da América do Sul.

\begin{tabular}{|c|c|c|c|c|c|c|c|c|c|}
\hline Identificação da Rocha & \# & Pol. & \begin{tabular}{|c|} 
Idade \\
Min.
\end{tabular} & $\begin{array}{c}\text { Idade } \\
\text { Max. }\end{array}$ & $\begin{array}{l}\alpha_{95} \\
\left(^{\circ}\right)\end{array}$ & $\mathbf{N}$ & $\begin{array}{l}\text { Plat } \\
\left({ }^{\circ} \mathrm{S}\right)\end{array}$ & \begin{tabular}{|c|}
$\begin{array}{l}\text { Plong } \\
\left({ }^{\circ} \mathrm{E}\right)\end{array}$ \\
\end{tabular} & Referências \\
\hline Grupo Mitu & 1 & $\mathrm{R} / \mathrm{N}$ & 245 & 260 & 5.7 & 6 & 71.4 & 303.6 & Gilder et al., 2003 \\
\hline Formação Tunas II & 2 & $\mathrm{R}$ & 251 & 299 & 5.2 & 24 & 74.1 & 25.9 & Tomezzoli, 2001 \\
\hline Formação La Tabla & 3 & $\mathrm{R}$ & 251 & 318 & 5.7 & 10 & 51 & 347 & Jesinkey et al., 1987 \\
\hline Formação Cerro Colorado-Caminiaga & 4 & $\mathrm{R}$ & 271 & 318 & 8 & 6 & 79 & 291 & Geuna \& Escosteguy, 2004 \\
\hline Formação Chancani & 5 & $\mathrm{R}$ & 271 & 318 & 8.8 & 3 & 85 & 359 & Geuna \& Escosteguy, 2004 \\
\hline Rincon Blanco & 6 & $\mathrm{R}$ & 271 & 318 & 4.9 & 19 & 77 & 294 & Geuna \& Escosteguy, 2004 \\
\hline Formation Tunas I & 7 & $\mathrm{R}$ & 276 & 299 & 5.4 & 19 & 63 & 13.9 & Tomezzoli \& Vilas, 1999 \\
\hline Granitos Lago Ranco & 8 & $\mathrm{R}$ & 297 & 307 & 18.8 & 7 & 57.4 & 323.5 & Beck et al., 1991 \\
\hline Formações Pular e Cas & 9 & $\mathrm{R} / \mathrm{N}$ & 299 & 318 & 9.6 & 10 & 57 & 350 & Jesinkey et al., 1987 \\
\hline Média de 2 a 8 & 11 & $\mathrm{R}$ & 251 & 307 & 12.5 & 7 & 72.1 & 342.7 & \\
\hline Grupo Santa Fé & 10 & $\mathrm{R}$ & 260 & 280 & 3.6 & 66 & 66.3 & 332.4 & Este trabalho \\
\hline
\end{tabular}

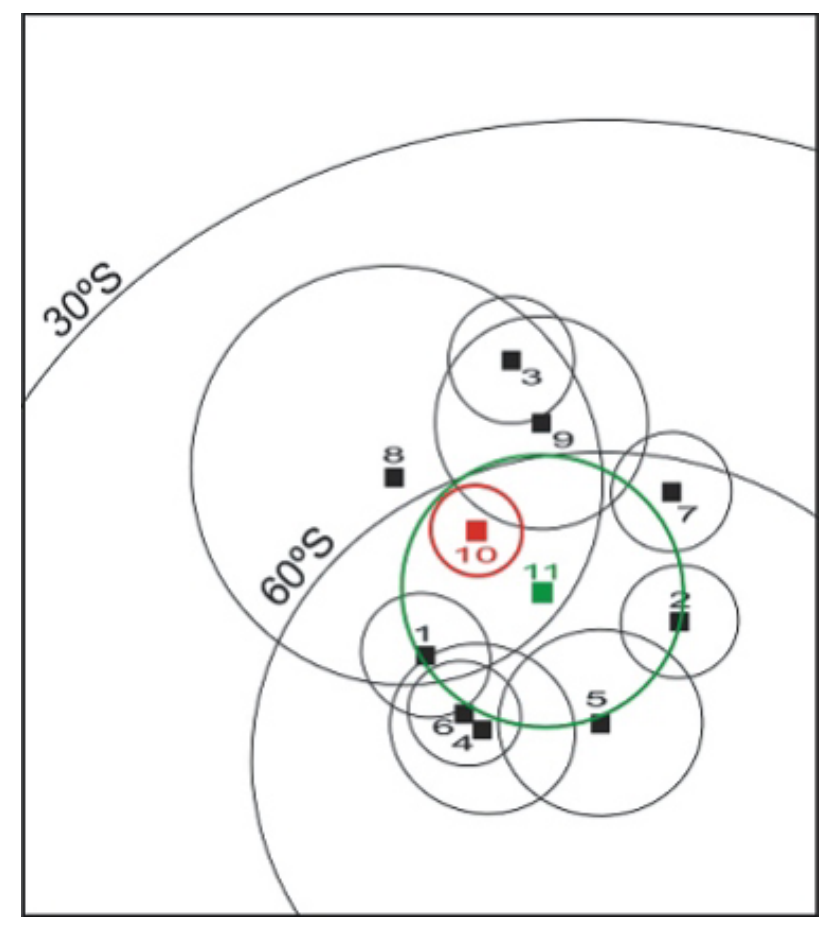

Figura 6.1. Pólos da América do Sul enumerados conforme a Tabela 6.1 e incluindo os círculos de confiança. 
Analisando este pólo paleomagnético do ponto de vista dos critérios estabelecidos por Van der Voo (1990) o único critério que este pólo não satisfaz é o número de sítios $(\mathrm{N}=6)$, por isso o pólo tem fator $\mathrm{Q}=6$. Entretanto, considera-se aqui $\mathrm{N}=6$ um número muito pequeno de sítios, pois possivelmente este pólo não elimina a variação secular do campo geomagnético e por isso pode estar deslocado.

O pólo paleomagnético 2 da Tabela 6.1 (Tomezzoli, 2001) possui o número de sítios $N=24$. A paleoflora e paleofauna da Formação Tunas indicam uma idade entre o Permiano inferior e superior. Não há presença de reversões, por isso esta formação é colocada no intervalo do SRPC. É de uma região dobrada e os dados de magnetização foram desdobrados em até $90 \%$ para que atingissem a menor dispersão. Este método pode ocasionar erros quanto à eliminação da variação secular. Tomezzoli (2001) compara este pólo (Tunas II) com outros pólos da América do Sul, tratando-o como compatível com pólos de regiões estáveis da América do Sul, embora seu círculo de confiança se superponha parcialmente apenas com um outro pólo (5).

O pólo paleomagnético 3 (Jesinkey et al., 1987) foi obtido com 10 sítios da Formação La Tabla, Norte do Chile de idade aproximada pós Carbonífero Inferior a pré Triássico Superior. Todas as direções são reversas e como este pólo paleomagnético se posiciona nas proximidades dos outros pólos encontrados para o Permo-Carbonífero é provável que este grupo também se insira no SRPC.

Os pólos paleomagnéticos 4, 5 e 6 (Geuna \& Escosteguy, 2004) referem-se a formações da Bacia Paganzo da Argentina; as idades dos três pólos é baseada em fósseis e paleoflora que indicam idades do Carbonífero Superior a Permiano Inferior. Os pólos 4 e 5 possuem número de sítios muito baixo ( 6 e 3 , respectivamente), por isso a média dos PGVs pode não eliminar a variação secular. Geuna \& Escosteguy (2004) afirmam que os pólos encontrados não são compatíveis com a região estável da América do Sul e tampouco com os dados de outros continentes como África e Austrália, devendo-se essa diferença à Fase Orogênica San Rafael (Permiano), rotações tectônicas ou datações incorretas. Todas as direções são reversas, portanto são todos inseridos no SRPC.

O pólo paleomagnético da Formação Tunas (chamado de Tunas I) (pólo 7 da Tabela 6.1) obtido por Tomezzoli \& Vilas (1999) é resultado de uma média de 19 PGVs de polaridade exclusivamente reversa (insere-se no SRPC). Tomezzoli \& Vilas (1999) 
afirmam que a Formação Tunas se depositou, deformou e remagnetizou, durante o Permo-Carbonífero. Este trabalho foi dividido em três grupos de dados de diferente locais: Estância San Carlos, Estância Golpe de Água e Córrego Toro Negro, que foram desdobrados respectivamente de $30 \%, 70 \%$ e $23 \%$ até que atingissem a menor dispersão de dados. Este método pode atribuir erros na direção média, porque se supõe que a menor distribuição dos dados corresponde à verdadeira distribuição. Ao utilizar a menor distribuição dos dados de cada local, a variação secular pode não ser eliminada corretamente.

O pólo paleomagnético 8 da Tabela 6.1 (Beck et al., 1991) é a média de 7 sítios de rochas graníticas do Sul do Chile. Possui uma datação K/Ar e ${ }^{40} \mathrm{Ar} /{ }^{39} \mathrm{Ar}$ de 297 a 307Ma. Todas as direções são reversas e pertencem ao SRPC e, segundo os autores, este pólo pode ser comparado com pólos de regiões estáveis porque não há grandes rotações que influenciem os dados. Entretanto o círculo de confiança demonstra uma incerteza muito grande na determinação do pólo.

O pólo paleomagnético 9 da Tabela 6.1 (Jesinkey et al., 1987) foi calculado com 10 PGVs de idade do Carbonífero Superior. Possui teste do conglomerado e reversões que podem ser o registro da base do SRPC e por sua vez, mais antigo que o pólo Santa Fé.

A Figura 6.1 mostra que os pólos paleomagnéticos da América do Sul se distribuem ao redor do pólo paleomagnético Santa Fé e que a média deles, se aproxima bem do pólo Santa Fé. Essa distribuição sugere que esses pólos devem estar afetados de variação secular, já que na maioria absoluta foram calculados com poucos sítios. O único pólo que atenderia ao critério de qualidade de Van der Voo $(\mathrm{N}>24)$ é o pólo Tunas II, com $\mathrm{N}=24$. Por outro lado, alguns dos pólos selecionados apresentam também problemas tectônicos mal resolvidos.

\subsection{Idade do Grupo Santa Fé}

Campos \& Dardenne (1994, 1997a) consideram o Grupo Santa Fé correlato ao Grupo Itararé da Bacia do Paraná que apresenta idade mínima de $260 \mathrm{Ma}$ (cinzas vulcânicas da Formação Rio Bonito que se sobrepõe imediatamente ao Grupo Itararé Coutinho et al., 1991). O SRPC situa-se no intervalo aproximado de 262-312Ma, mas 
alguns intervalos de polaridade normal já foram identificados na base do SRPC e também a aproximadamente 280Ma (por exemplo, Alva-Valdivia et al., 2002). Considerando que os resultados paleomagnéticos obtidos para o Grupo Santa Fé são de polaridade exclusivamente reversa, a idade de deposição provavelmente está compreendida entre 260-280Ma.

Quando comparado à curva de deriva polar aparente (CDPA) para o Gondwana (Figura 6.3) de McElhinny et al. (2003), o pólo Santa Fé (SF-2, rotacionado para a África usando os mesmos parâmetros de McElhinny et al., op.) coloca-se próximo ao trecho da curva referente à idade de 260Ma (Permiano), embora um pouco deslocado os círculos de confiança de SF-2 e dos pólos médios da curva não se sobrepõem. Entretanto deve-se levar em conta a baixa qualidade de alguns pólos utilizados nas médias e os problemas tectônicos que afetam as regiões envolvidas, tanto da América do Sul (Argentina e Chile) como Austrália. Além do mais as rotações dos vários blocos para compor o Gondwana podem não ser ainda suficientemente precisas.

Na Figura 6.3 compara-se também o pólo paleomagnético do Grupo Santa Fé (SF-1) com a CDPA proposta por Gilder et al. (2003). O pólo SF não é compatível com essa curva no intervalo de idade correspondente (260-280), mesmo porque os pólos existentes são problemáticos, como já se demonstrou. Esta curva de deriva é, portanto, inadequada nesse intervalo, devendo-se incorporar mais dados de qualidade para uma redefinição da CDPA.

\subsection{Paleogeografia e Paleolatitude}

A paleogeografia do período Permo-Carbonífero é um assunto muito discutido em Paleomagnetismo devido ao fato de ocorrer uma sobreposição parcial da placa Norte Americana e da placa Sul Americana nas reconstruções paleogeográficas (Figura 6.2). De acordo com Muttoni et al. (2003) essa sobreposição de latitudes ocorre porque na realidade a disposição dos continentes não se encaixa no Pangea ' $A$ ', onde a placa Norte Americana se localiza ao norte da placa Sul Americana. A reconstrução dada pelo autor é chamada de Pangea 'B', na qual a placa Norte Americana se localizaria mais a noroeste da Placa Sul Americana. Já para outros autores, como Torsvik \& Van der Voo (2002) essa sobreposição de latitudes é dada pela contribuição significativa de 
componentes não dipolares do campo geomagnético terrestre deste período, e afirmam também que este problema pode estar associado a erros de inclinação da magnetização de rochas sedimentares.

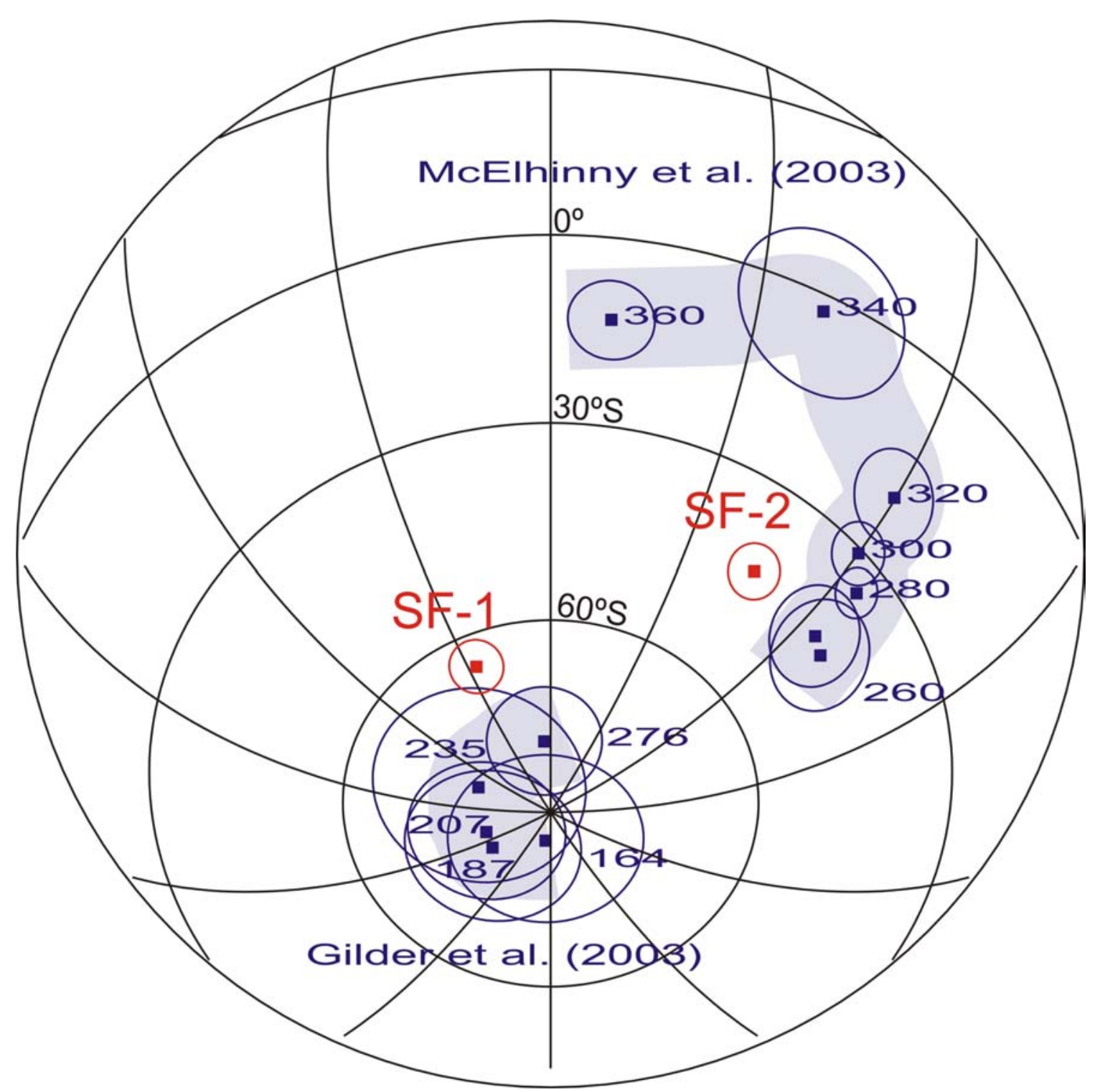

Figura 6.3. Comparação do pólo encontrado com curvas de deriva polar aparente a América do Sul (Gilder et al., 2003) e para o Gondwana (McElhinny et al., 2003). SF-1 em coordenadas atuais e SF-2 rotacionado para coordenadas da África com o ângulo de rotação utilizado por McElhinny et al. (2003). 


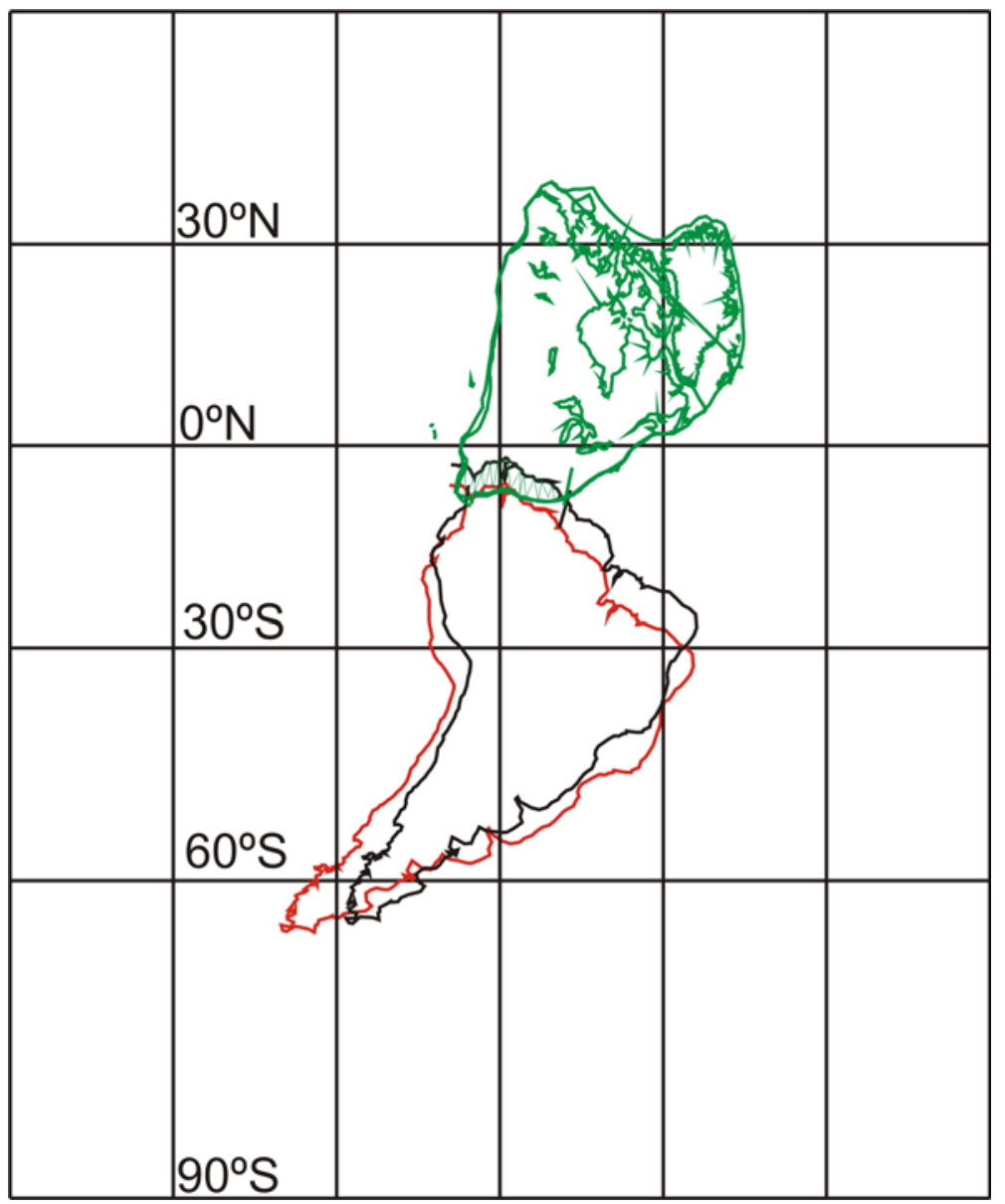

Figura 6.2. Reconstrução feita por Torsvik \& Van der Voo (2002), com a sobreposição das placas preenchida em verde. E em vermelho a reconstrução da América do Sul baseada no pólo paleomagnético Santa Fé.

Para visualizar o problema discutido por Torsvik \& Van der Voo (2002), foi feita uma reconstrução para a Laurentia e para a América do Sul com a média dos pólos entre 260 e $280 \mathrm{Ma}$ utilizados por estes autores. Esta reconstrução é apresentada na Figura 6.2. Porém a reconstrução da placa Sul Americana baseada no pólo Santa Fé posiciona a placa Sul Americana mais ao sul, praticamente eliminando a superposição. Portanto, o que explicaria a sobreposição de latitudes encontradas por outros autores não seria uma configuração de Pangea 'B', nem um modelo diferente para o campo geomagnético e sim a falta de dados de boa qualidade para a placa Sul Americana.

A paleolatitude encontrada para a região de amostragem do Grupo Santa Fé foi de $39.2^{\circ}$, cerca de $22^{\circ}$ mais ao sul que a localização atual. Para o padrão climático atual, uma massa continental localizada a $39^{\circ} \mathrm{S}$ apresenta gelo apenas em grandes altitudes, 
diferente do caso das rochas do Grupo Santa Fé que registram a ocorrência do evento glacial Permo-Carbonífero (Rocha-Campos et al., 2003) e que não estaria relacionado com grandes altitudes. Este resultado mostra que o evento glacial do Permo-Carbonífero atingiu latitudes de $39^{\circ} \mathrm{S}$, indicando uma configuração climática diferente da atual.

\subsection{Considerações Finais}

O pólo paleomagnético apresentado para o grupo Santa Fé é um pólo-chave para a definição da CDPA da América do Sul para o Neopaleozóico. Satisfaz à maioria dos critérios de confiança estabelecidos na literatura especializada e, portanto, deve ser visto como um pólo de referência para a idade correspondente.

Neste trabalho optou-se por calcular um único pólo para o Grupo Santa Fé (Formação Floresta) e não discutir mais profundamente eventuais diferenças, como apontadas em capítulo anterior, entre os dados dos membros Lavado e Brejo do Arroz, mesmo porque o número de sítios deste último são muito reduzidos. Por outro lado estes membros se interdigitam e as possíveis diferenças podem ser apenas locais. Entretanto, quando se analisa apenas os dados do Membro Lavado (Brandt \& Ernesto, 2005), notase que os parâmetros estatísticos dos PGVs aproximam-se mais de uma distribuição fisheriana e dos níveis de dispersão devidos somente à variação secular. Para as subseções A1 e A3 do Membro Lavado encontrou-se o pólo paleomagnético localizado em $326.8^{\circ} \mathrm{E}$ e $62.8^{\circ} \mathrm{S}\left(\mathrm{N}=37 ; \alpha_{95}=3.6 ; \mathrm{k}=43\right)$. Quanto às coordenadas, o pólo do Grupo Santa Fé aqui apresentado e o pólo do Membro Lavado não diferem significativamente, mas a distribuição dos dados se altera, indicando que pode haver diferença de idades entre os dois membros.

Essa questão poderá ser resolvida futuramente com amostragem complementar do Membro Brejo do Arroz. Além disso, a seção B do Membro Lavado, nas proximidades de Canabrava, permite não só densificar a amostragem, como também estendê-la para a Formação Tabuleiro, permitindo, assim, verificar o possível registro de inversões de polaridade e definir melhor o intervalo de idades do Grupo Santa Fé. 


\section{REFERÊNCIAS}

Alva-Valdivia, L. M., Goguitchaichvili, A., Grajales, M., Dios, A. F. de, UrrutiaFucugauchi, J., Rosales, C., Morales, J. 2002. Further constraints for PermoCarboniferous magnetostratigraphy: case study of the sedimentary sequence from San Salvador - Pantlanoaya (Mexico). C. R. Geoscience 334: 811-817.

Beck, M.E., Garcia, A., Burmester, R.F., Munizaga,F., Herve, F., Drake, R.E. 1991. Paleomagnetism and geochronology of late Paleozoic granitic rocks from the Lake District of southern Chile: Implications for accretionary tectonics. Geology (19): 332-335.

Brandt, D., Ernesto, M. 2005. Paleomagnetismo e magnetoestratigrafia do Grupo Santa Fé (Bacia Sanfranciscana, MG): Idade e paleolatitude da sedimentação glacial. Submetido à Rev. Bras. Geof.

Butler, R.F. 1992. Paleomagnetism: Magnetic Domains to Geologic Terranes. Blackwell Sci. Publications, Boston: 319.

Campos, J.E.G. \& Dardenne, M.A., 1994. A Glaciação Neopaleozóica na Porção Meridional da Bacia Sanfranciscana. Rev. Bras. Geoc. 24(2): 65-76.

Campos, J.E.G. \& Dardenne, M.A., 1997a. Estratigrafia e sedimentação da Bacia Sanfranciscana: Uma Revisão. Rev. Bras. Geoc. 27(3): 269-282.

Coutinho, J.M.V., Hachiro, J., Coimbra, A.M. e Santos, P.R. 1991. Ash-fall derived vitroclastic tuffaceos sediments in the Permian of the Paraná Basin and a study of its provenance. In: Seventh International Gondwana Symposium, Instituto de Geociências, USP: 147-160.

Dardenne, M.A., Campos, J.E.G. 2003. Glacigenic facies stratigraphy of the Santa Fé Group in the Sanfranciscana Basin. 3rd Latinamerican Congress of Sedimentology., Belém, PA, 18-19.

Dunlop, D.J., Özdemir, O. 1997. Rock Magnetism: Fundamentals and frontiers. Cambridge University Press, 573.

Fisher, R.A. 1953. Dispersion on a sphere. Proc. R. Soc. London Ser. A 217, 295-305.

Geuna, S.E., Escosteguy, L.D. 2004. Palaeomagnetism of the Upper CarboniferousLower Permian transition from Paganzo basin, Argentina. Geophys.J.Int. (157): 1071-1089.

Gilder, S., Rousse, S., Farber, D., McNulty, B., Sempere, T., Torres, V., Palacios, O. 2003. Post-Middle Oligocene origin of paleomagnetic rotations in Upper Permian to Lower Jurassic rocks from northern and southern Peru. Earth Planet.Sci.Letters (210):233-248.

Irving, E. 1977. Drift of the major continental blocks since the Devonian. Nature (270): 304-309.

Jesinkey, C., Forsythe, R.D., Mpodozis, C., Davidson, J. 1987. Concordant late Paleozoic paleomagnetizations from the Atacama Desert: implications for tectonic models of the Chilean Andes. Earth Planet.Sci.Letters (85): 461-472. 
Kirschvink, J. L., 1980. The least-squares line and plane and the analysis of paleomagnetic data. Geophys. J. R. Astr. Soc. (62): 699-718.

Lienert, B. R. 1991. Monte Carlo simulation of errors in the anisotropy of magnetic susceptibility: a second-rank symmetric tensor, J. Geophys. Res. (96): 19,53919,544 .

Lowrie, W. 1990. Identification of Ferromagnetic Minerals in a Rock by Coercivity and Unblocking Temperature Properties. Geophysical Research Letters, 17: 159-162.

McElhinny, M.W. \& McFadden, P.L. 2000. Paleomagnetism, Continents and Oceans. Acdemic Press, Internat. Geophys. Series (73): 386pp.

McElhinny, M. W., Powel, C. M., Pisarevsky, S. A., 2003. Paleozoic Terranes of eastern Australia and the drift history of Gondwana. Tectonophysics 362: 41-65.

Muttoni, G., Dent, D.V. \& Channell, J.E.T. 1996. Evolution of Pangea: paleomagnetic constraints from the Southern Alps, Italy. Earth Plant. Sci. Letters (140): 97-112.

Muttoni, G., Kent, D. V., Garzanti, E., Brack, P., Abrahamsen, N., Gaetani, M. 2003. Early Permian Pangea 'B' to Late Permian Pangea 'A'. Earth and Planetary Science Letters. 215: 379-394.

Néel, L., 1949. Théorie du trainage magnétique des ferromagnéetiques en grains fines avec applications aux terres cuites. Ann. Geophys. 5: 99-136.

Néel, L., 1955. Some theoretical aspects of rock magnetism. Adv. Phys. 4: 191-243.

Rocha-Campos, A. C., Santos, P. R. dos, Tomio, A., Salvetti R. A. P. 2003. Alternative Paleogeography of Late Paleozoic Glacial Rocks of NW State of Minas Gerais. 3rd Latinamerican Congress of Sedimentology, Belém, PA: 144-146.

Serviço Geológico do Brasil - CPRM, 2002. Projeto São Francisco. Folha SE.23-V-BSão Romão e Folha SE.23-V-D-João Pinheiro.

Serviço Geológico do Brasil - CPRM. Bacias Sedimentares Fanerozóicas do Brasil. Disponível em $<$ http://www.cprm.gov.br/gis/tect_fanerozoicas.htm>. Acesso dia 12/01/2006.

Sgarbi, G. N. C., Sgarbi, P. B. A., Campos, J. E. G., Dardenne, M. A., Penha, U. C. 2001. Bacia Sanfranciscana: O Registro Fanerozóico da Bacia do São Francisco. In: C. P. Pinto, M. A. Martins Neto (eds). Bacia do São Francisco: Geologia e Recursos Naturais. SBG MG, Belo Horizonte: 93-138.

Souza-Lima, W., Junior, G. P. H. 2003. Bacias Sedimentares Brasileiras. Phoenix, ano 5, v. 50. Disponível em <http: //www.phoenix.org.br/Phoenix50_Fev03.html $>$. Acesso dia 12/01/2006.

Tauxe, L. 2002. Paleomagnetic Principles and Pratice. Kluwer Academic Publishers, Dordrecht.

Tomezzoli, R.N., Vilas, J.F. 1999. Palaeomagnetic constraints on the age of deformation of the Sierras Australis thrust and fold belt, Argentina. Geophys.J.Int. (138): 857-870.

Tomezzoli, R.N. 2001. Further palaeomagnetic results from the Sierras Australes fold and thrust belt, Argentina. Geophys.J.Int. (147): 356-366. 
Torsvik, T. H., Van der Voo, R. 2002. Refining Gondwana and Pangea palaeogeography: estimates of Phanerozoic non-dipole (octupole) fields. Geophys. J. Int. 151: 771-794.

Van der Voo, R., 1990. The reliability of paleomagnetic data. Tectonophysics 184: 1-9.

Van der Voo, R. \& Torsvik, T. 2001. evidence for late Paleozoic and Mesozoic nondipole fields provides an explanation for the Pangea reconstruction problems. Earth Planet. Sci. Letters (187): 71-81.

Zijderveld, J. D. A., 1967. A. C. Demagnetization of Rocks: Analysis of Results. In: Methods and Techiniques in Paleomagnetism, D. W. Collison et. al. (eds.), Elsevier, Amsterdam: 254-286. 